\title{
Optimization of a flexible multi-generation system based on wood chip gasification and
} methanol production

\author{
Lythcke-Jørgensen, Christoffer Ernst; Clausen, Lasse Røngaard; Algren, Loui ; Bavnhøj Hansen, \\ Anders; Münster, Marie; Gadsbøll, Rasmus Østergaard; Haglind, Fredrik
}

\section{Published in:}

Applied Energy

Link to article, DOI:

10.1016/j.apenergy.2016.08.092

Publication date:

2017

Document Version

Peer reviewed version

Link back to DTU Orbit

Citation (APA):

Lythcke-Jørgensen, C. E., Clausen, L. R., Algren, L., Bavnhøj Hansen, A., Münster, M., Gadsbøll, R. Ø., \& Haglind, F. (2017). Optimization of a flexible multi-generation system based on wood chip gasification and methanol production. Applied Energy, 192, 337-359. https://doi.org/10.1016/j.apenergy.2016.08.092

\section{General rights}

Copyright and moral rights for the publications made accessible in the public portal are retained by the authors and/or other copyright owners and it is a condition of accessing publications that users recognise and abide by the legal requirements associated with these rights.

- Users may download and print one copy of any publication from the public portal for the purpose of private study or research.

- You may not further distribute the material or use it for any profit-making activity or commercial gain

- You may freely distribute the URL identifying the publication in the public portal 


\title{
Optimization of a flexible multi-generation system based on wood chip gasification and methanol production
}

Christoffer Lythcke-Jørgensen $^{a *}$, Lasse Røngaard Clausen ${ }^{a}$, Loui Algren ${ }^{b}$, Anders Bavnhøj Hansen ${ }^{b}$, Marie Münster ${ }^{c}$, Rasmus Østergaard GadsbølI ${ }^{d}$, Fredrik Haglind $^{a}$

${ }^{a}$ Technical University of Denmark, Department of Mechanical Engineering

${ }^{b}$ Energinet.dk

${ }^{c}$ Technical University of Denmark, Department of Management Engineering

${ }^{d}$ Technical University of Denmark, Department of Chemical and Biochemical Engineering

* Corresponding author. Email: celjo@mek.dtu.dk. Phone: +45 304272 00. Nils Koppels Allé 403, 2800 Kgs. Lyngby, Denmark.

\begin{abstract}
Flexible multi-generation systems (FMGs) consist of integrated and flexibly operated facilities that provide multiple links between the different sectors of the energy system. The present study treated the design optimization of a conceptual FMG which integrated a methanol-producing biorefinery with an existing combined heat and power (CHP) unit and industrial energy utility supply in the Danish city of Horsens. The objective was to optimize economic performance and minimize total $\mathrm{CO}_{2}$ emission of the FMG which was required to meet the local district heating demand plus the thermal utility demand of the butchery. The design optimization considered: Selection, dimensioning, location and integration of processes; operation optimization with respect to both hourly variations in operating conditions over the year as well as expected long term energy system development; and uncertainty analysis considering both investment costs and operating conditions.
\end{abstract}

Applying a previously developed FMG design methodology, scalable models of the considered processes were developed and the system design was optimized with respect to hourly operation over the period 2015-2035. The optimal design with respect to both economic and environmental performance involved a maximum-sized biorefinery located next to local industry rather than in connection with the existing CHP unit. As the local industry energy demands were limited when compared to the biorefinery dimensions considered, process integration synergies were found to be marginal when compared to the economic and environmental impact of the biorefinery for the present case.

Assessing the impact of uncertainties on the estimated FMG performances, the net present value (NPV) of the optimal design was estimated to vary within the range $252.5 \mathrm{M} €$ to $1471.6 \mathrm{M} €$ in response to changes of $\pm 25 \%$ in investment costs and methanol price, and considering two different electricity price scenarios. In addition, a change in the interest rate from $5 \%$ to $20 \%$ was found to reduce the lower bound of the NPV to $181.3 \mathrm{M} €$ for reference operating conditions. The results suggest that the applied interest rate and operating conditions, in particular the methanol price, would have a much higher impact on the economic performance of the designs than corresponding uncertainties in investment costs. In addition, the study 


\section{Greek letters}

$56 \sigma$

$57 \omega$

$58 \lambda$

\section{Subscripts}

$\begin{array}{lll}60 & i & \text { Period } \\ 61 & k & \text { Process }\end{array}$

\section{Abbreviations}

63 CCHP Combined cooling, heat and power

$64 \mathrm{CHOP}$ Characteristic operating pattern

$65 \mathrm{CHP}$

66 FMG

67 NPV

68 RES

69 SOEC

70 TCE

Net present value

Process dimension

Installation decision (integer)

Load

Combined heat and power

Flexible multi-generation systems

Net present value

Renewable energy sources

Solid oxide electrolysis cell

Total $\mathrm{CO}_{2}$ emission impact
Investment cost, process $k$

Reference investment cost, process $k$

Hourly operation result

Operation cost, process $k$

Power factor for economy-of-scale calculations

Interest rate

Number of years from installation date

Duration of period $i$

Present value factor of period $i$

Total $\mathrm{CO}_{2}$ emission impact

Hourly $\mathrm{CO}_{2}$ emission impact of operation
[M€]

[M€]

[M€]

$[\mathrm{ME} / \mathrm{h}]$

$[\mathrm{ME} / \mathrm{h}]$

$[-]$

$[-]$

$[-]$

[h]

[h]

[MTon]

[MTon] 


\section{Introduction}

The transition towards sustainable energy systems based on intermittent renewable energy sources (RES) necessitates the development of efficient means for balancing generation and consumption of energy services. While focus previously was centred on developing smart grid technology for the power grid, recent studies suggests that the challenge of balancing generation from renewables is better appreciated from a holistic energy system perspective in order to avoid suboptimal, sector-based solutions [1][2]. This holistic approach has been referred to as a Smart Energy System approach, and it promotes the integration of power, thermal and gas grids, and the use of various energy storage options in combination in order to achieve secure and sustainable energy systems based on renewable sources [3].

However, synergies from integrating energy conversion process in multi-generation systems are not considered directly using the smart energy systems approach. These synergies may be of great importance in the transition towards sustainable energy systems [4], especially regarding biomass conversion where it has been suggested that systematic consideration of process integration synergies may increase the energy- and cost-efficiency of the conversion as well as the overall system [5].

Responding to this, the concept of flexible multi-generation systems (FMG) was recently introduced by Lythcke-Jørgensen et al. [6]. Here, FMGs were defined as integrated systems that generate multiple energy services and are able to adjust operation in response to fluctuating demand patterns and varying price schemes in the overarching energy system. The hypothesis is that local or regional FMGs may support the balancing of an energy system with large shares of variable RES in a cost-effective way by linking the different parts of the energy system with local supply systems. By converting energy in response to demand and price variations, FMGs may be regarded as virtual energy system valves as conceptually illustrated in Figure 1, making the development of FMGs a relevant topic.

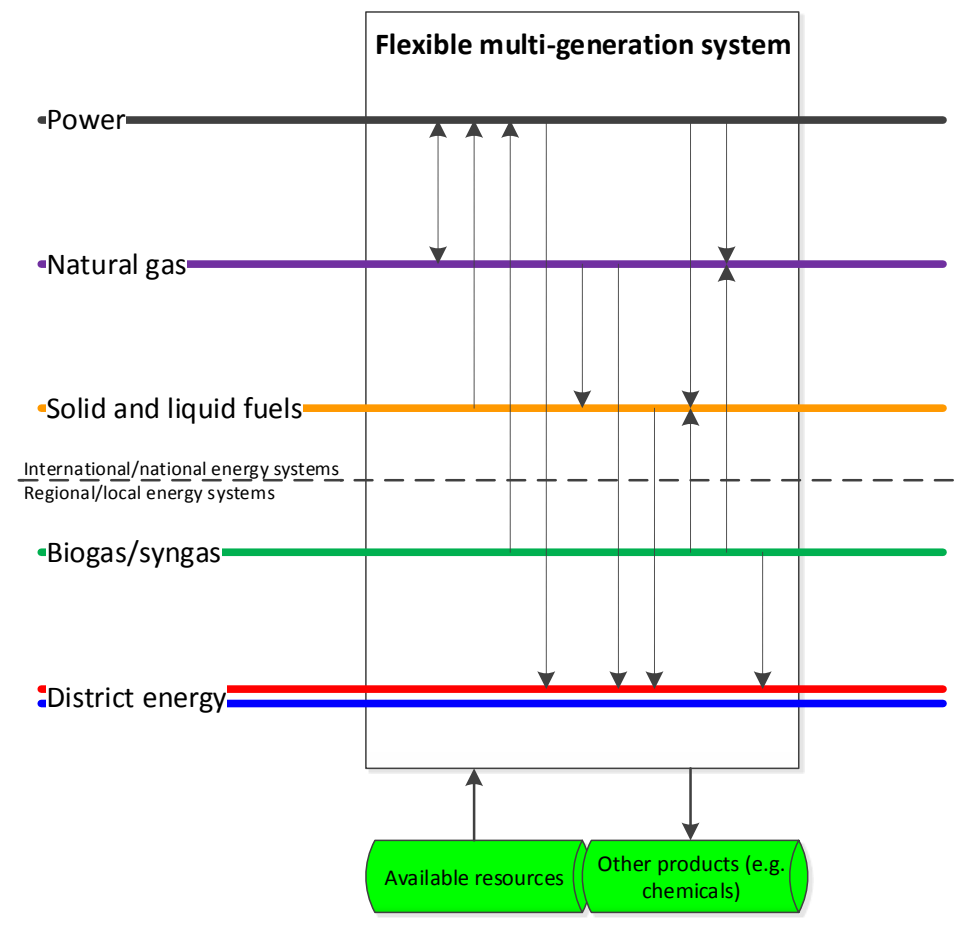


The development of FMGs is complex and involves multiple design aspects. Within these, five aspects are considered of special relevance:

1. Process selection and dimensioning

2. Systematic process integration

3. Variable short-term operation conditions, including hourly, diurnal, weekly and seasonal changes in demands and generation from variable RES

4. Variable long-term operation conditions, responding to developments in the energy system

5. Uncertainty analysis

Numerous approaches for designing multi-generation systems have been presented in literature $[7,8]$, but as discussed in Lythcke-Jørgensen et al. [6], none of these are able to consider all five listed aspects coherently. For instance, Liu et al. [9] developed a stochastic, multi-objective mixed integer-nonlinear programming model for designing polygeneration ${ }^{1}$ systems based on several previous works, but did not consider short-term operation or process integration. Based on the OSMOSE tool ${ }^{2}$, Maréchal et al. [10] presented a multi-period, multi-objective methodology for designing multi-generation systems which considered technology selection and dimensioning, process integration, selection of facility location selection, flexible operation, and network layout. Fazlollahi et al. developed three add-ons to the methodology to allow for the structured reduction of operation periods [11], inclusion of daily thermal storages [12] and detailed design of distribution networks [13]. However, the combined methodology only considered variations in one external operating condition, namely outdoor temperature, meaning that flexible interactions with other parts of the energy system were not considered. In addition, uncertainties were not addressed in the combined methodology. In consequence, a novel methodology for designing FMGs was introduced in Lythcke-Jørgensen et al. [6] which included all the listed aspects as well as others, including biomass supply chains.

A number of specific FMG concepts have been treated in case studies. Regarding FMGs integrating the heat and power layers, Lund et al. [2] presented the case of Skagen combined heat and power (CHP) plant which included three CHP units, thermal energy storage, a peak load gas boiler, and an electrical boiler. The system effectively created a dual link between the electricity grid and the district heating system as the plant was able to both generate electricity and heat directly as well as convert electricity to heat. In a study of a comparable system, Sorknæs et al. [14] found that the system's ability of provide electricity grid balancing could increase the overall CHP operation load by $25 \%$ and reduce net heat production costs by $5 \%$ for a specific heating network. However, it was questioned if the results would be valid in case multiple comparable systems adopted a similar operation strategy due to the limited size of the balancing market. In two closely related works, Capuder and Mancarella [15][16] studied seven different schemes for supplying electricity and heating in the UK. In a study, the group found that FMG schemes consisting of CHP units, electric heat pumps, and thermal energy storage may reduce investment and operating costs as well as aggregate emission levels when compared to conventional or less flexible heat-and-electricity supply

\footnotetext{
${ }^{1}$ In a recent review, Adams and Ghouse [52] defined 'polygeneration' as a thermochemical process which simultaneously generates electricity and produces at least one type of chemical or fuel without being a co- or tri-generation unit ${ }^{2}$ OSMOSE is a computer aided process engineering tool, developed at EPFL in the IPESE group, for designing and optimizing integrated energy systems. For more information, refer to [46] or the IPESE group homepage: http://ipese.epfl.ch/.
} 

systems in the UK. The group further found that FMG schemes may allow for reductions in both expected costs and risks under long-term price uncertainty scenarios when compared to less flexible systems [17].

Another branch of FMGs integrate the power, heating and cooling layers and are also referred to as combined cooling, heating and power (CCHP) systems. Piacentino et al. [18] introduced a methodology for maximizing the net present value (NPV) of CCHP systems for building clusters by considering component selection, dimensioning, and operation optimization with respect to hourly energy demands. Zhou et al. [19] presented a methodology for designing distributed CCHP systems based on a two-stage stochastic programming model which accounted for selection, dimensioning, and operation optimization of combinations of equipment under uncertain operating conditions. Rubio-Maya et al. [20] presented a heuristic, two-level methodology for designing local FMGs for CCHP and fresh water generation and in a case study found that an integrated natural-gas based scheme would be profitable when compared to a stand-alone solution.

Among FMGs integrating the power grid and liquid fuel layer, Chen et al. [21] studied an FMG using coal and biomass to generate electricity and co-produce naphtha, diesel and methanol. The group found that flexible systems in general achieved higher NPVs than static systems, however at the cost of larger investments. In three related works, Lythcke-Jørgensen et al. [22-24] studied an FMG concept integrating cellulosic ethanol production with a CHP unit, creating a virtual link between the electricity, heating and fuel systems. Models and process integration strategies were analysed and optimized, and it was found that the lack of flexibility in the ethanol production induced inefficient operation during periods with high electricity prices, causing the entire system to be economically uncompetitive in an energy system with a large share of wind power [22]. At the same time, the average exergy efficiency of the ethanol production was markedly reduced when compared to the exergy efficiency in optimal operation [23]. It was further found that a diseconomy-of-scale trend applied for the ethanol production in the FMG under the set conditions as reductions in integration synergies exceeded the benefits from economy-of-scale in investment and operating costs [24]. These outcomes illustrate some of the challenges faced when developing flexible technologies for energy systems with large shares of varying RES.

In two recent studies, Lythcke-Jørgensen et al. $[6,25]$ studied an FMG concept combining heat and power generation with the production of cellulosic ethanol and biogas-based synthetic natural gas. It was demonstrated how operation flexibility is a central aspect when assessing the performance of FMGs [25], and that systematic process integration ought to be considered when optimizing the design of FMGs [6]. The outcomes illustrate the importance of systematically considering the five previously listed design aspects when developing FMGs.

This paper treats the development of a conceptual FMG based on an existing CHP unit and local industry. The FMG was developed for producing methanol from biomass and supplying district heating and industrial energy utilities. Using the state-of-the-art design optimization methodology presented in LythckeJørgensen et al. [6], the FMG was optimized with the aim of maximizing NPV and minimizing the total $\mathrm{CO}_{2}$ emission impact (TCE) from operating the system over the period 2015-2035. Technologies considered include a two-stage biomass gasifier, a solid oxide electrolysis cell (SOEC), a methanol production facility, industrial heat pumps, and novel heat and gas infrastructures, altogether linking the power, district heating, natural gas, and fuel layers of the energy system. 
The present work addresses the knowledge gap between process level optimization and energy system optimization by taking system level variations into account when designing energy conversion systems. The novelty of the study lies in the design optimization that coherently considers: Process selection and dimensioning; systematic process integration using pinch analysis; consideration of local demands for energy services and local infrastructures; performance assessment with respect to hourly variations in operating conditions as well as long-term energy system development; and uncertainty analysis considering uncertainties in important design parameters. In addition, the design optimization assesses performance variations with respect to various energy system scenarios and applied interest rate in the NPV calculation. To the authors' best knowledge, no previous work has presented such comprehensive approach to the design optimization of an FMG concept.

In this paper, the case study considered and the applied optimization methodology are described in Section 2. Results of the design optimization and systematic assessment of uncertainties are presented in Section 3 , while Section 4 features a discussion on potential drawbacks of the work and recommendations for future research within this field. A conclusion on the study is presented in Section 5. Appendix A features a full documentation of the process modelling, while Appendix $B$ includes documentation on the structuring of energy system scenario datasets in the present work.

\section{Methods}

\subsection{Case description}

The case study treated in this paper was centred on the Horsens Kraftvarmeværk, a back-pressure CHP unit in the Danish city of Horsens with a population of 56,536 [26]. The back-pressure CHP unit has a full-load capacity of $7 \mathrm{MWe}$ and $25 \mathrm{MJ} / \mathrm{s}$ district heating and consists of a steam Rankine cycle with two 5 ton/hour waste incineration boilers. In addition, a gas turbine is installed on site, which is capable of boosting district heating production with $8 \mathrm{MJ} / \mathrm{s}$ [27]. Furthermore, a large butchery located approximately $9 \mathrm{~km}$ from the CHP unit was included in the case study. The thermal utility demand of the butchery was assumed covered by natural gas in the reference case. A sketch of the reference system is presented in Figure 2.

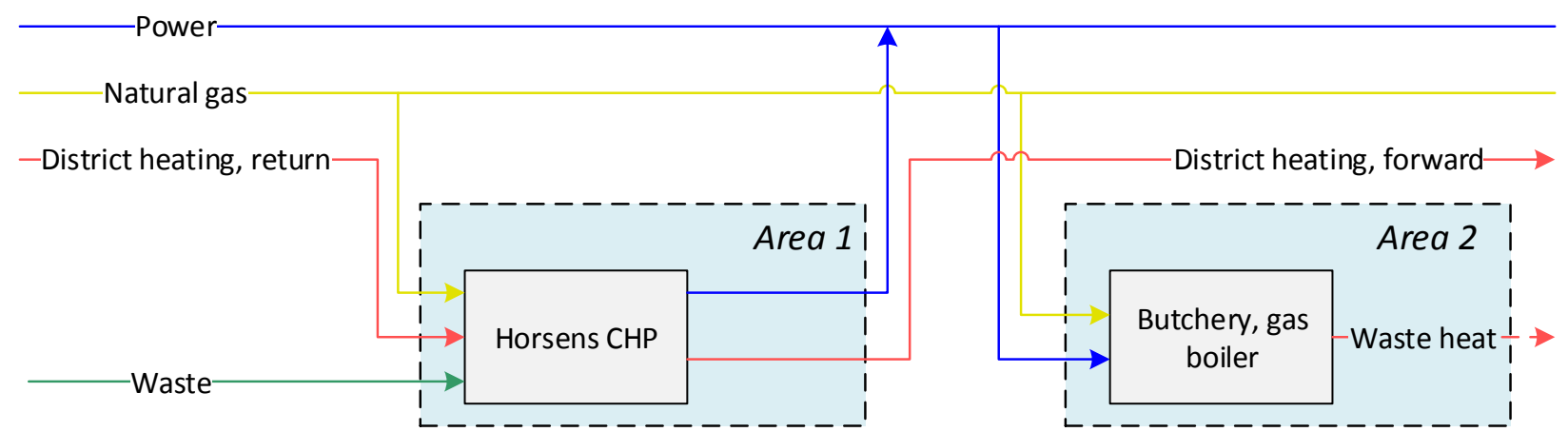

Figure 2: Conceptual sketch of energy flows in the reference system.

The case study treated the retrofitting of the reference system by installing a biorefinery, consisting of a two-stage biomass gasifier [28], a solid oxide electrolysis cell (SOEC), and a methanol production facility. The biorefinery was to be installed either next to the CHP unit or the butchery, and the installation of a product gas pipeline between the two areas was considered. In addition, investment in a district heating 
link to the butchery area was considered in order to cover parts of the butchery thermal utility demands through district heating using ammonia-water hybrid heat pumps. The conceptual retrofit options are illustrated in Figures 3 and 4.

207 The hypothesis is that the present FMG is advantageous in an energy system with large shares of intermittent renewable power generation as it may absorb additional power in periods with excess generation (low power prices) and convert it to methanol by boosting product gas from the gasifier with hydrogen from the SOEC [29]. Similarly, it may reduce power consumption in periods with high power prices by reducing SOEC load and thereby methanol production. At the same time, process integration is used to optimize the overall energy conversion efficiency of the system, potentially increasing thermodynamic and economic efficiencies when compared to non-integrated facilities $[6,25]$. Process heat demands of the butchery could further be met through process integration with the biorefinery, by compression-based ammonia-water hybrid heat pumps using district heating as heat source, or by product gas combusted in the butchery gas boiler. In addition, non-reacted product gas may replace parts of the gas utility demand of the butchery, thereby replacing natural gas. In total, this tentative combination of processes allows for a flexible energy supply system capable of converting biomass resources to demanded energy services in order to replace fossil fuels while at the same time providing links between the electricity, district heating, natural gas, and fuel sectors of the overarching energy system.

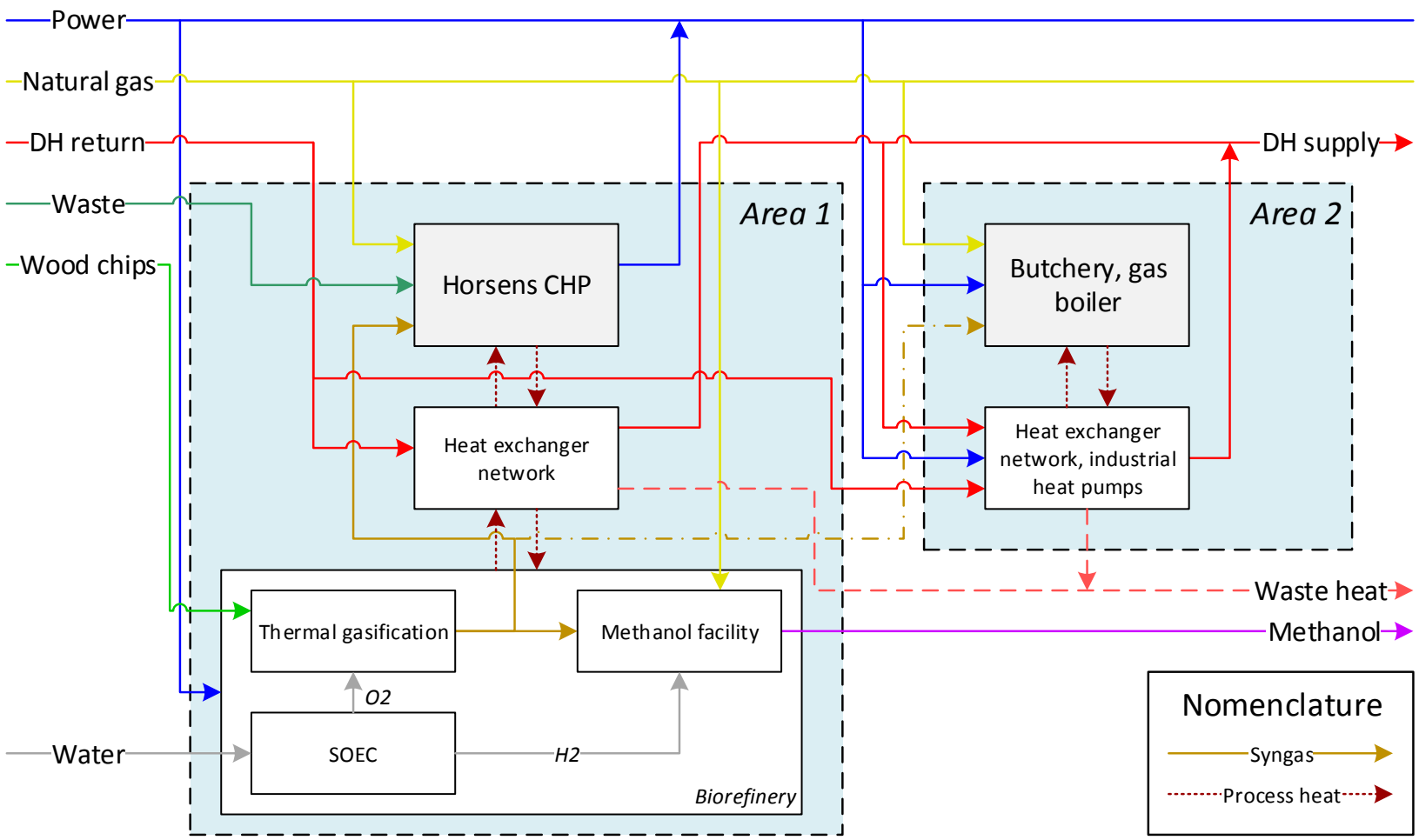

Figure 3: Conceptual sketch of energy flows in 'Retrofit Scenario A' with the biorefinery installed next to the CHP unit. Notice that the process heat flows represent feasible heat integration options between the facilities. Process integration options within the facilities are not illustrated in the figure for simplicity. 


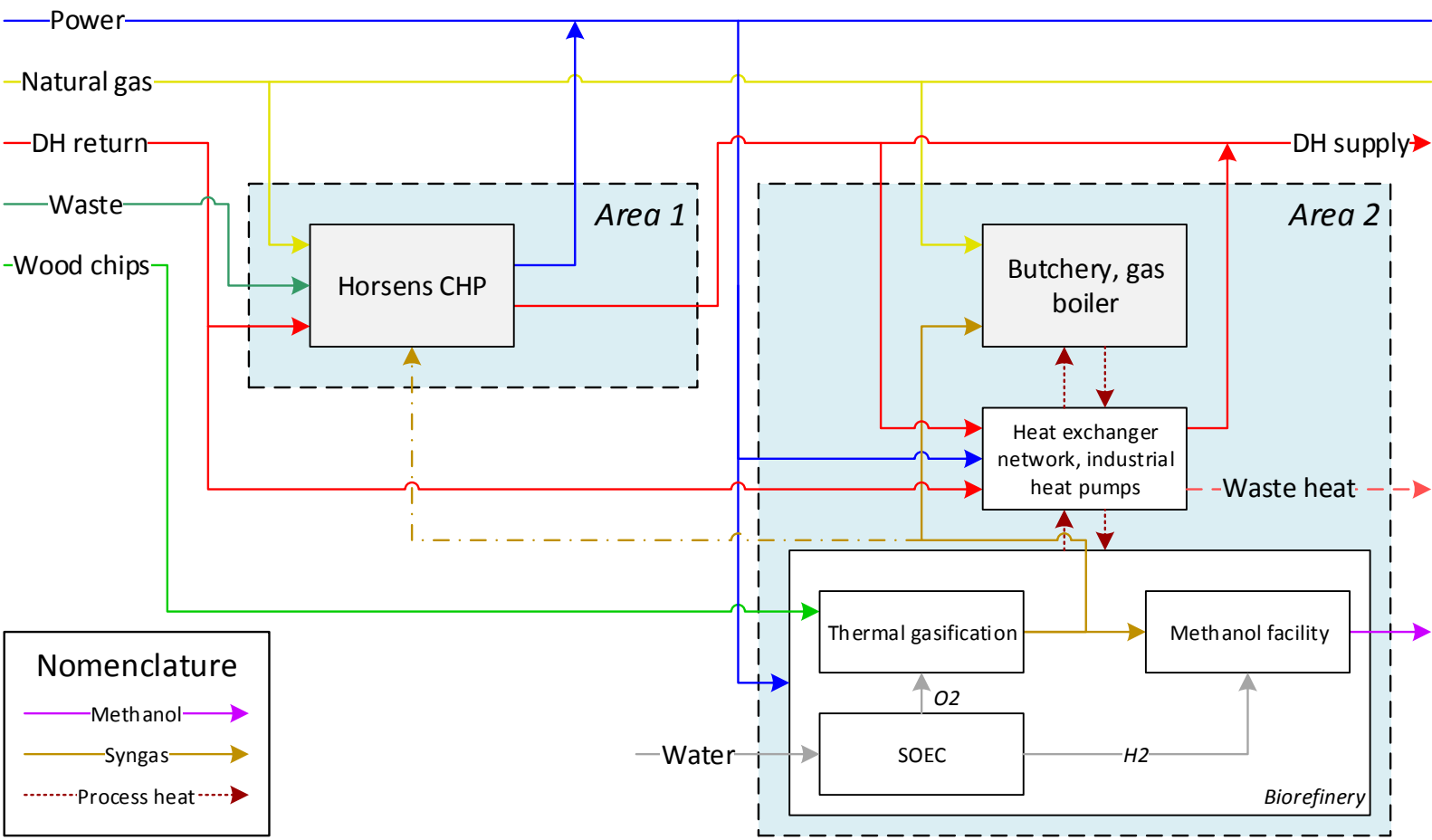

Figure 4: Conceptual sketch of energy flows in 'Retrofit Scenario B' with the biorefinery installed next to the butchery. Notice that the process heat flows represent feasible heat integration options between the facilities. Process integration options within the facilities are not illustrated in the figure for simplicity.

\subsection{Methodology}

As mentioned, a previously developed methodology for designing FMGs [6] was applied in this work. The methodology structure is presented in Figure 5.

In short, the methodology applied is capable of conducting multi-objective design optimization of an FMG superstructure whilst considering:

- Selection, location, and dimensioning of processes

- Systematic heat and mass integration using pinch analysis

- Flexible operation optimization with respect to both short-term market fluctuations and long-term energy system development through the application of the Characteristic Operating Pattern (CHOP) method [30]

- Investment planning

- Global sensitivity and uncertainty analysis

- Consideration of local resource availability, biomass supply chains, and market sizes

- Variable part-load performance

Input data to the design methodology includes process and equipment models, energy system data, local resource data, and life cycle inventory data. The input data is structured prior to the optimization, which is conducted by a hybrid genetic algorithm/mixed integer-linear programming model. The optimization generates a database of designs with deterministic performances, for which Pareto analysis can be conducted. A number of interesting designs may then be picked for further assessment, including sensitivity and uncertainty analysis. 


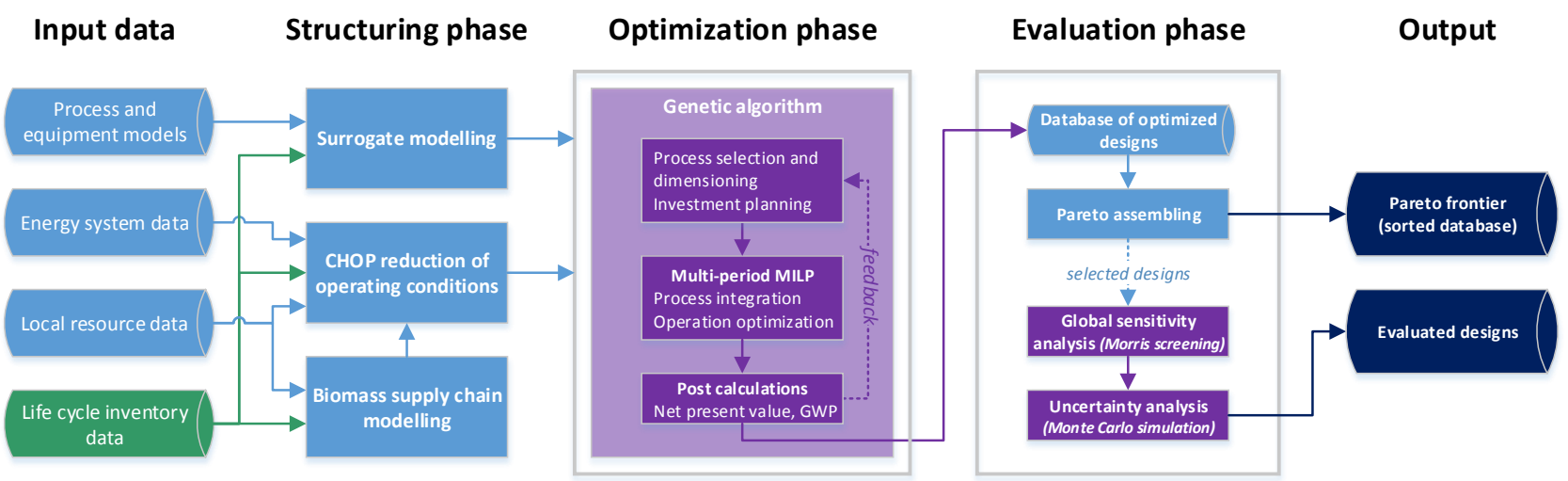

Figure 5: Design methodology structure [6]. The structure illustrates how input data is first structured, following which the primary optimization is conducted. The outcomes of the optimization are afterwards assessed further.

In the present case, the retrofit design was optimized with the aim of maximizing net present value (NPV) and minimizing the total $\mathrm{CO}_{2}$ emission impact (TCE) from operating the system over the period 2015-2035. The TCE is a simple measure of the difference between $\mathrm{CO}_{2}$ emissions from plant operation and replaced $\mathrm{CO}_{2}$ emissions in the reference system. Investment planning and wood chips supply chains are not considered in the study.

\subsection{Modelling and assumptions}

\subsubsection{Horsens CHP and district heating system}

The two waste incineration boilers at Horsens CHP have a capacity of 5 tonnes of waste per hour each, and their minimum operation load is 75\% [27][31]. Due to the demand for processing of local waste, the boilers were assumed to be operated at all times. The Rankine cycle was operated in back-pressure mode with a nominal power generation capacity of $7 \mathrm{MWe}$ and a nominal heat generation capacity of $25 \mathrm{MJ} / \mathrm{s}$ [27]. The steam Rankine cycle has two condensers in order to optimize the overall exergy efficiency: One operated at $0.3 \mathrm{bar}$, and the other at $0.8 \mathrm{bar}$ [27]. To comply with the district heating forward and return temperatures, it was assumed that $75 \%$ of the condensation heat was generated in the 0.8 bar condenser and that the generation of power and heat was directly proportional to the load.

Assuming that the exhaust gas from the gas turbine was used directly for district heating generation, with a nominal capacity $8 \mathrm{MJ} / \mathrm{s}$ [27], the nominal gas consumption and electricity generation capacities were calculated using estimated values of electrical efficiency and overall energy efficiency of the gas turbine.

The district heating system was assumed to have a maximum district heating demand equal to the heat generation potential of Horsens CHP. A forward/return temperature scheme of $90^{\circ} \mathrm{C} / 40^{\circ} \mathrm{C}$ was assumed, and seasonal differences were neglected.

Operation data used in the modelling of Horsens CHP are presented in Table 1. Functions relating energy and mass flows in the system to operation variables are presented in Appendix A.

Table 1: Operation data used in the modelling of Horsens CHP.

\begin{tabular}{|l|l|l|}
\hline Parameter & Notation & Value \\
\hline RANKINE CYCLE & & \\
\hline
\end{tabular}


waste incineration capacity nominal power generation nominal district heating generation nominal heat in 0.8 bar condenser nominal heat in 0.3 bar condenser minimum load variable operating costs energy efficiency

\begin{tabular}{|c|c|}
\hline$\sigma_{\text {ran }}$ \\
$P_{\text {ran }}$ \\
$\dot{Q}_{\text {ran }}$ \\
$\dot{Q}_{\text {ran, } h p 0}$ \\
$\dot{Q}_{\text {ran }, l p 0}$ \\
\hline$\lambda_{\text {ran,min }}$ \\
$c_{\text {ran }, v a r}$ \\
$\eta_{\text {ran }}$
\end{tabular}

$33.3 \mathrm{MJ} / \mathrm{s}[27]^{\mathrm{a}}$

$7.0 \mathrm{MWe}$ [27]

$25.0 \mathrm{MJ} / \mathrm{s}$ [27]

$18.75 \mathrm{MJ} / \mathrm{s}$

$6.25 \mathrm{MJ} / \mathrm{s}$

0.75 [27][31]

$15.9 € / M W h$ waste $[31]^{b}$

0.96 [31]

\section{GAS TURBINE}

nominal gas consumption

electrical efficiency

energy efficiency

off-gas temperature

cooled exhaust gas temperature

variable operating costs

minimum load

\section{DISTRICT HEATING SYSTEM}

maximum district heating demand

forward temperature

return temperature

${ }^{a}$ : Corresponding to a processing capacity of 10 ton/h of waste [31].

${ }^{\text {b }}$ : Corresponding to 53.0 Euro/ton of waste [31].

c: The minimum load is assumed constrained due to emission restrictions [31].

\subsubsection{Butchery}

Based on specialist knowledge collected by Energinet.dk, the shares of thermal utility demands in a typical Danish butchery running on natural gas are presented in Table 2 . The values were used to describe the thermal utility demands of the butchery in the case study. It was assumed that the butchery had a nominal energy utility demand of $6.43 \mathrm{MWth}^{3}$, that the thermal parts of the utility demand was met by a natural gas boiler in the reference case, and that excess heat from thermal utility demands above $100^{\circ} \mathrm{C}$ could be recovered and utilized directly for district heating generation. Operation data used in the modelling of the butchery is summarized in Table 3. Functions for energy and mass flows in the system are presented in Appendix A.

Table 2: Average thermal utility demands in Danish butcheries.

\begin{tabular}{|l|l|c|}
\hline Thermal utility demand & Share of energy demand & Assumed temperature requirements \\
\hline Boiling and evaporation & $4 \%$ & $110^{\circ} \mathrm{C}$ \\
\hline Cleaning & $37 \%$ & $60^{\circ} \mathrm{C}$ \\
\hline Process gas & $35 \%$ & - \\
\hline Room heating and losses & $24 \%$ & $35^{\circ} \mathrm{C}$ \\
\hline
\end{tabular}

Table 3: Operation data used in the modelling of the butchery.

\begin{tabular}{|l|c|l|}
\hline Parameter & Notation & Value \\
\hline Maximum thermal utility demand & $\sigma_{\text {ind }}$ & $6.43 \mathrm{MJ} / \mathrm{s}$ \\
\hline Gas boiler operating costs & $c_{g b, v a r}$ & $0.5 € / M W h[31]$ \\
\hline
\end{tabular}

\footnotetext{
${ }^{3}$ This capacity represents the capacity of an average butchery in Denmark, according to Energinet.dk.
} 


\subsubsection{Biorefinery}

The biorefinery considered was based on an upscaled version of the Two-stage Biomass Gasifier, a gasifier concept which can generate a product gas almost free of $\operatorname{tar}\left(5 \mathrm{mg} / \mathrm{Nm}^{3}\right)$ and with a low methane content [32]. The gasifier is air-blown and has been demonstrated in a size up to $1.5 \mathrm{MW}_{\text {th }}$ input [33]. The gas from the gasifier is used by the biorefinery for methanol production and process heat generation, by the CHP for heat generation, or by the butchery for process gas and heat. When the gasifier is air-blown, only a part of the product gas can be converted to methanol because of nitrogen build-up in the methanol synthesis loop. In order to increase the biomass to methanol conversion, an SOEC is included in the biorefinery. The SOEC can supply pure oxygen for the gasifier and hydrogen for the methanol synthesis.

In the present work, a surrogate model of the biorefinery was developed based on the models presented by Clausen et al. [28][29]. The gasifier was assumed fed by imported wood chips. The division of reference components into surrogate models is illustrated in Figure 6. In addition to this, an SOEC model was developed. Finally, a gas burner for burning un-reacted product gas was assumed installed on-site with the biorefinery.

The integration of the SOEC increases the operational flexibility of the biorefinery, and the biorefinery can generally be said to operate in one of the following three modes: 1) air-blown, 2) oxygen-blown, 3 ) hydrogen boosted. In mode 2, the SOEC operates in part load, based on the oxygen demand of the gasifier. In mode 3, the SOEC operates at full load based on the maximum feasible addition of hydrogen in the methanol synthesis.

The energy conversion ratio of biomass-to-methanol for running in air-blown, oxygen-blown, and hydrogen-boosted operation modes were identified from simulations of the reference model [28]. Assuming linear relations for SOEC loads between the three described operating modes, the biomass-tomethanol energy ratio of the biorefinery as a function of SOEC load is plotted in Figure 7. The figure clearly shows a bend in the curve at an SOEC load of 0.37 , where the oxygen-blown operating mode is defined. The slope of the curve to the left of the oxygen-blown point is about two times higher than the slope to the right, meaning that the conversion of electricity to methanol, by means of an SOEC, is twice as efficient below the full oxygen-blown operation point. The SOEC can therefore be allowed to operate in oxygenblown mode at a higher electricity price than what could be advantageous for the hydrogen-boosted mode. 


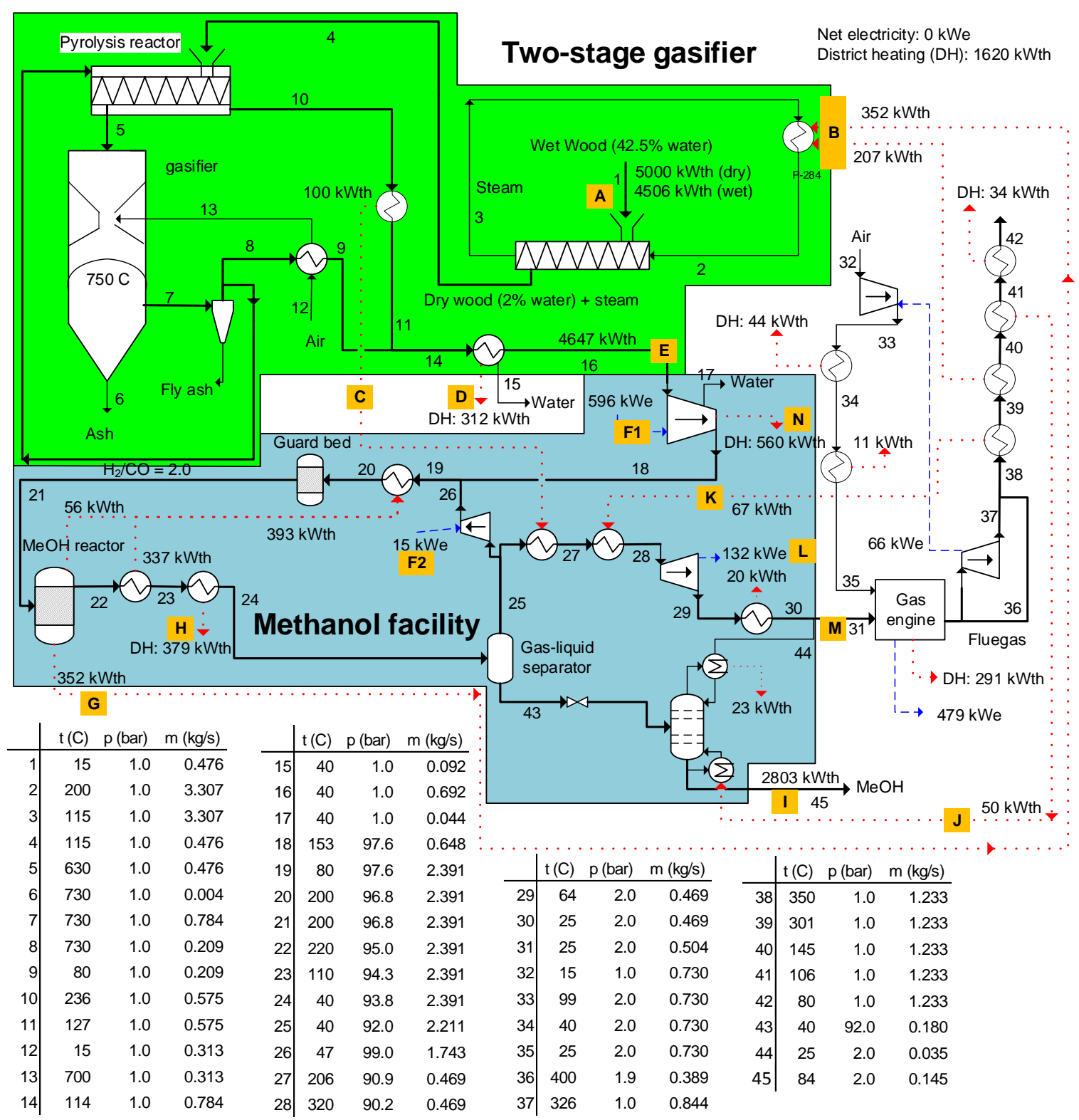

Figure 6: Reference model of the wood chip-based two-stage gasifier and methanol facility, with surrogate model division outlined. Flows denoted with a letter are included in the surrogate model, see Appendix A. Modified version of a figure from Clausen [28].

323 In hydrogen-boosted mode almost all the carbon in the product gas could theoretically be converted to 324 methanol, but in the present biorefinery design the carbon-to-methanol conversion is constrained to $89 \%{ }^{4}$. In oxygen-blown mode $66 \%$ of the carbon in the product gas is converted to methanol (practically all CO is converted), while in air-blown mode $41 \%$ of the carbon is converted to methanol. Only in air-blown mode will the unreacted product gas contain significant amounts of energy and therefore allow for export of this mass flow to the butchery.

\footnotetext{
${ }^{4}$ The carbon conversion could be increased to $97 \%$ by recirculating the $\mathrm{CO}_{2}$ from the topping column (stream 44 on Figure 6) to the methanol synthesis loop.
} 


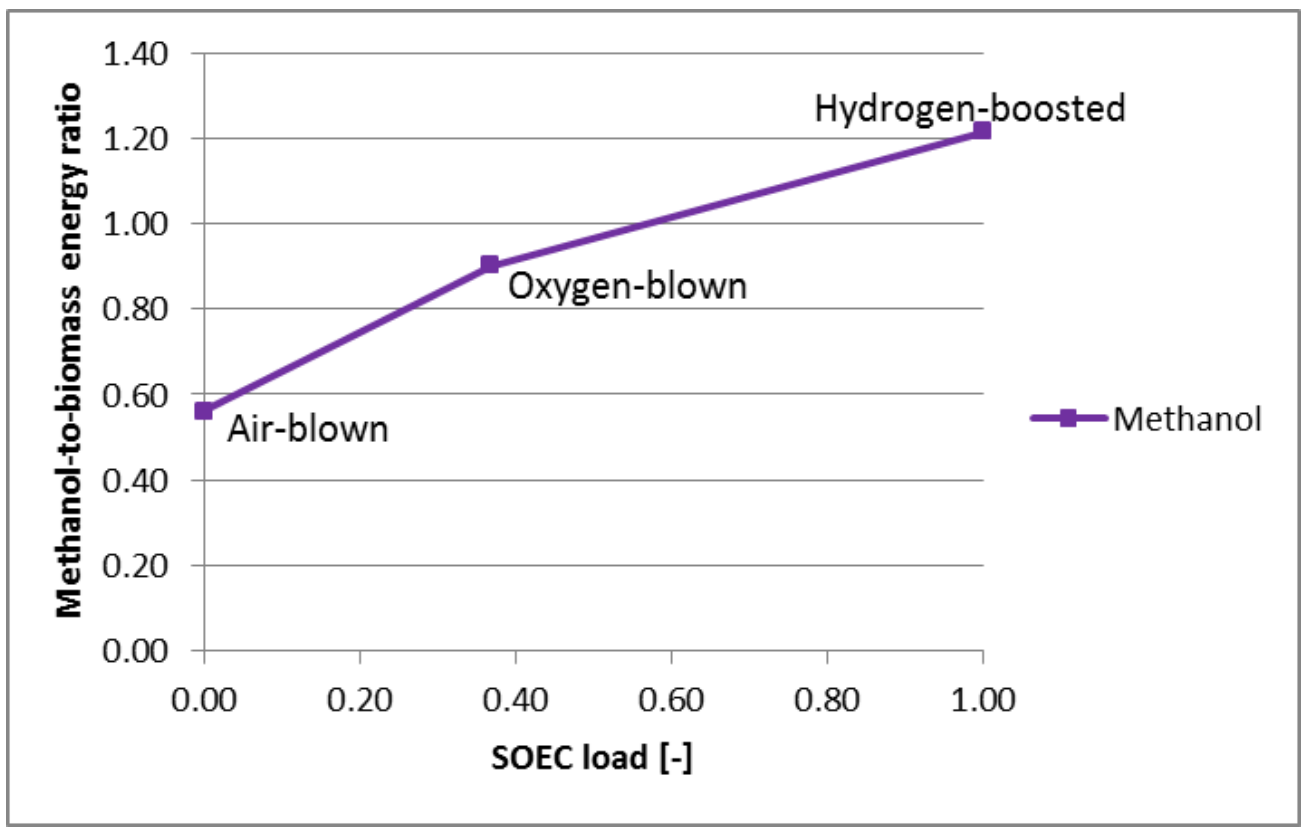

Figure 7: Methanol-to-biomass energy conversion ratio for different SOEC loads.

Operation data used in the biorefinery model is summarized in Table 4, while functions for energy and mass flows in the system are included in Appendix A. It was assumed that operation and maintenance costs for the biorefinery, excluding resource consumption costs, were independent of operation. Sales of excess oxygen were not considered.

Table 4: Operation data used in the biorefinery model.

\begin{tabular}{|c|c|c|}
\hline Parameter & Notation & Value \\
\hline Biomass-to-product gas efficiency & $\eta_{\text {gasifier }, N C V}$ & $0.93[28]$ \\
\hline SOEC power-to-hydrogen efficiency & $\eta_{S O E C, N C V}$ & $0.92^{\mathrm{a}}$ \\
\hline Reference dimension & $\sigma_{0, b i o}$ & $360 \mathrm{MJ} / \mathrm{s}$ wood chips $[34]$ \\
\hline Reference investment cost & $C_{i n v, b i o 0}$ & $314.9 \mathrm{M} €[31][34]^{\mathrm{b}}$ \\
\hline Reference fixed annual operating costs & $c_{o p, b i o}$ & $9.2 \mathrm{M} € /$ year [31][34] ${ }^{\mathrm{b}}$ \\
\hline
\end{tabular}

${ }^{\mathrm{a}}$ Efficiency calculated by assuming an inlet temperature of $770{ }^{\circ} \mathrm{C}$ and an outlet temperature of $800{ }^{\circ} \mathrm{C}$ combined with the assumption that $5 \%$ of the electricity is lost (heat losses, inverter loss, and electricity consumption by blowers etc.) [35].

${ }^{b}$ : Investment and fixed operating costs are calculated for the combined biorefinery, with an SOEC dimensioned for maximum

339 hydrogen boost of the methanol production.

\subsubsection{Infrastructure and industrial heat pumps}

In the case study, investments in district heating and gas infrastructure for connecting the two areas were considered. The distance between the areas was set to be $9 \mathrm{~km}$. Costs of infrastructure investments used in the case study are summarized in Table 5. Infrastructure operation and maintenance costs were neglected.

The forward district heating water could be utilized as heat source for ammonia-water hybrid heat pumps that may provide process heating at temperatures of up to $140^{\circ} \mathrm{C}$ [36]. In the case study, it was assessed if such heat pumps would be beneficial for meeting the boiling and evaporation thermal utility demands of the butchery. A scalable surrogate model of an ammonia-water hybrid heat pump was developed based on a reference model presented by Jensen et al. [36]. Data used in the modelling of the heat pump are presented in Table 6, while functions for thermal and mass flows are summarized in Appendix A. 
Table 6: Data used in the ammonia-water hybrid heat pump model.

\begin{tabular}{|l|c|l|}
\hline Parameter & Notation & Value \\
\hline Source inlet temperature & $T_{\text {source }}$ & $90^{\circ} \mathrm{C}$ \\
\hline Source temperature difference & $\Delta T_{\text {source }}$ & $50^{\circ} \mathrm{C}$ \\
\hline Sink inlet temperature & $T_{\text {sink }}$ & $120^{\circ} \mathrm{C}$ \\
\hline Sink temperature difference & $\Delta T_{\text {sink }}$ & $10 \mathrm{~K}$ \\
\hline Temperature lift & $\Delta T_{\text {lift }}$ & $50^{\circ} \mathrm{C}^{\mathrm{a}}$ \\
\hline Coefficient of performance & $C O P$ & $2.9[36]^{\mathrm{b}}$ \\
\hline Reference investment cost & $C_{\text {inv } h p 0}$ & $0.43 \mathrm{M} €^{\mathrm{b}}$ \\
\hline Reference heat pump dimension & $\sigma_{\text {hp } 0}$ & $1.0 \mathrm{MJ} / \mathrm{s} \mathrm{sink} \mathrm{heat}^{\mathrm{b}}$ \\
\hline Operating cost & $C_{o p, h p}$ & $4900 € /(\mathrm{MJ} / \mathrm{s}-$ year $)[31]^{\mathrm{c}}$ \\
\hline
\end{tabular}

a: The temperature lift is set as the difference between average DH temperature and sink outlet temperature.

${ }^{b}$ : The values are taken for an ammonia-water hybrid heat pump with sink and source temperature lifts of $10 \mathrm{~K}$ and with optimized ammonia fraction and circulation ratio for the given operating scheme, as predicted by Jensen et al. [36].

${ }^{c}:$ The heat pump operating costs are assumed equal to the highest predicted operating costs of an electric district heating heat pump [31].

\subsection{Energy system data}

Three reference years were used for describing the energy system development over the period 2015-2035, namely 2015, 2025, and 2035. The energy system data for 2015 was assumed repeated for the first six years, the data from 2025 was assumed repeated for the following eight years, while the data for 2035 was assumed repeated for the final six years of the period.

Table 7: Fuel prices in the reference years.

\begin{tabular}{|l|l|l|l|l|}
\hline Parameter & 2015 scenario & 2025 scenario & 2035 scenario & Reference \\
\hline Natural gas & $9.66[€ / G]$ & $9.93[€ / G]$ & $10.51[€ / G]$ & {$[39]$} \\
\hline Wood chips & $6.52[€ / G]$ & $6.90[€ / G]$ & $7.52[€ / G]]$ & {$[39]$} \\
\hline Methanol & $21.25[€ / G]]^{\mathrm{a}}$ & $24.63[€ / \mathrm{G}]]^{\mathrm{a}}$ & $28.34[€ / \mathrm{G}]]^{\mathrm{a}}$ & {$[39]$} \\
\hline Gasoline & $20.73[€ / \mathrm{GJ}]$ & $23.68[€ / \mathrm{GJ}]$ & $25.42[€ / \mathrm{GJ}]$ & {$[39]$} \\
\hline $\mathrm{CO}_{2}$ quota, intermediate estimate & $7.41[€ /$ ton] & $13.62[€ /$ ton] & $42.21[€ /$ ton] & {$[39]$} \\
\hline Oil $^{\mathrm{b}}$ & $13.72[€ / \mathrm{GJ}]$ & $16.51[€ / \mathrm{GJ}]$ & $18.16[€ / \mathrm{GJ}]$ & {$[39]$} \\
\hline
\end{tabular}

a: The methanol price is calculated as the estimated gasoline value plus the estimated economic value of avoided $\mathrm{CO}_{2}$ emissions with respect to $\mathrm{CO}_{2}$ quota value.

${ }^{b}$ : To be consistent with data, the fuel oil price corresponds the to the predicted oil price from [39] and not the actual oil price, which by March 2016 is around $40 \mathrm{USD} /$ barrel, corresponding 6.11 [ $€ / \mathrm{GJ}$ ] [40].

As illustrated in Figure 3 and Figure 4, the FMG interacts with the surroundings through the import and/or export of power, natural gas, district heating, waste, wood chips, and methanol. Waste is assumed to be free as the FMG is obliged to provide waste processing. Prices for natural gas, wood chips and methanol in each of the three reference years are presented in Table 7. 
The FMG was considered to be the sole provider of district heating and industry energy utility, so the district heating demand and industry energy utility demand had to be met by the FMG at all times.

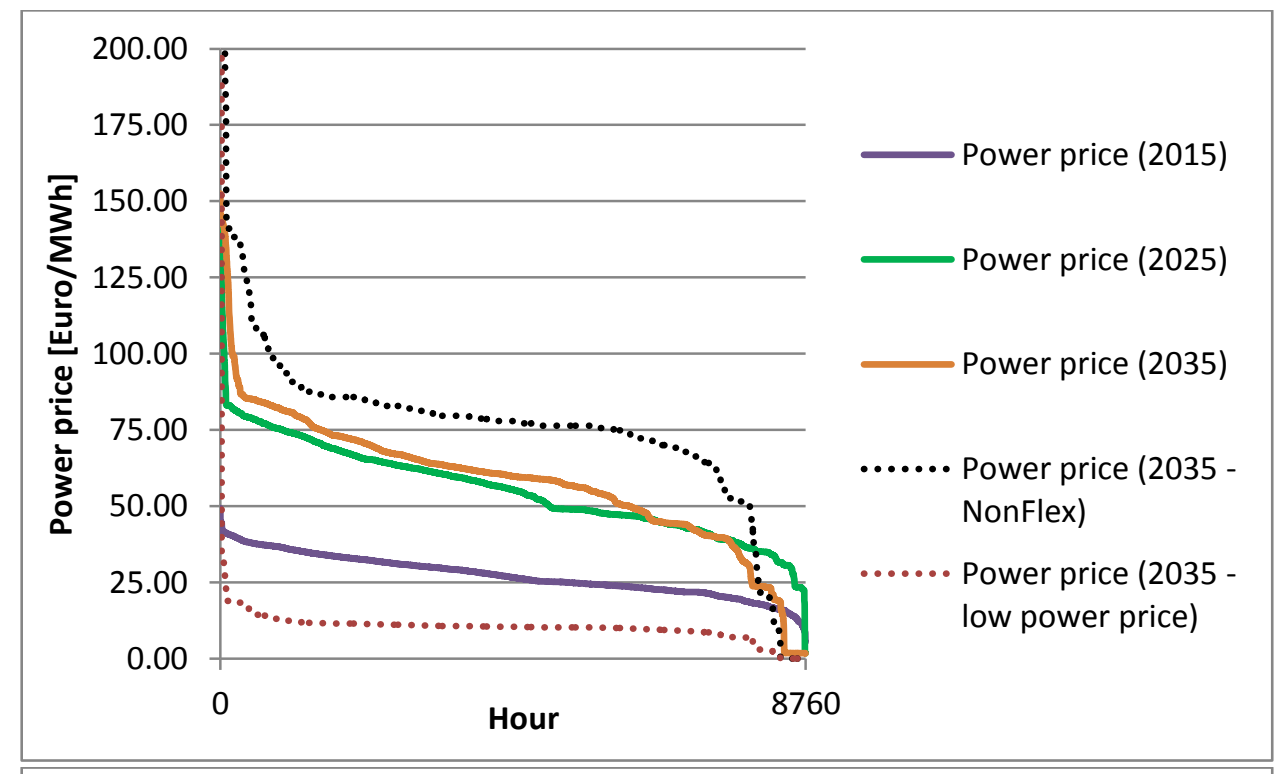

Figure 8: Annual duration curves for the power price and relative district heating demand in Horsens in each of the three

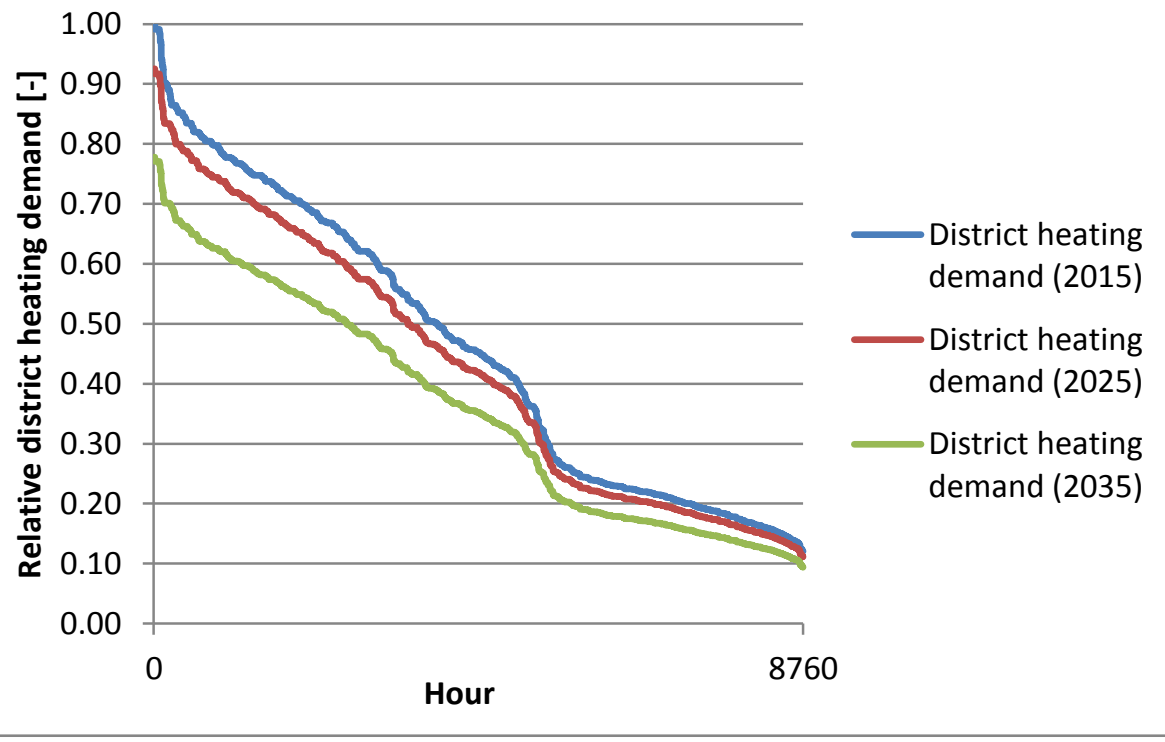
scenarios.

For the reference scenario, the district heating demand and expected power price were extracted from simulations within the energy system model SIFRE [41]. SIFRE is an energy systems modelling tool developed to handle flexible, integrated energy systems and include accurate representation of new components such as renewable energy production, flexible demand, and new types of energy carriers as for instance various green gasses. SIFRE simulates each power plant individually and solves the unit commitment problem for an optimal production schedule. SIFRE simulates the existing day-ahead market and generates electricity prices which are used as boundary conditions, assuming that the operation of the FMG is not affecting the national prices considerably. The three scenario simulations for 2015, 2025 and 2035 were based on Energinet.dk's analysis assumptions [42]. Duration curves for the power price and district heating demand for each of the scenarios are presented in Figure 8. In addition, two other duration 
curves for 2035 are included in the figure: one from the NonFlex scenario, in which power prices were extracted from a different energy system simulation scenario based on the assumption that smart grid technology will not obtain a major breakthrough in Denmark, meaning that the operation of electric vehicles, individual heat pumps and electrolysis plants is not optimized for the electricity price [43]. And a low power price scenario, in which power prices in 2035 has been reduced by a factor 7.5 as compared to the Nonflex scenario, to assess what impact extremely low and highly variable power prices would have on the system performance.

Data on annual butchery thermal utility demand was assumed similar for each year of the period. The demand profile was provided by Energinet.dk and is based on the hourly natural gas consumption of a number of Danish food industries in 2014. The duration curve is presented in Figure 9.

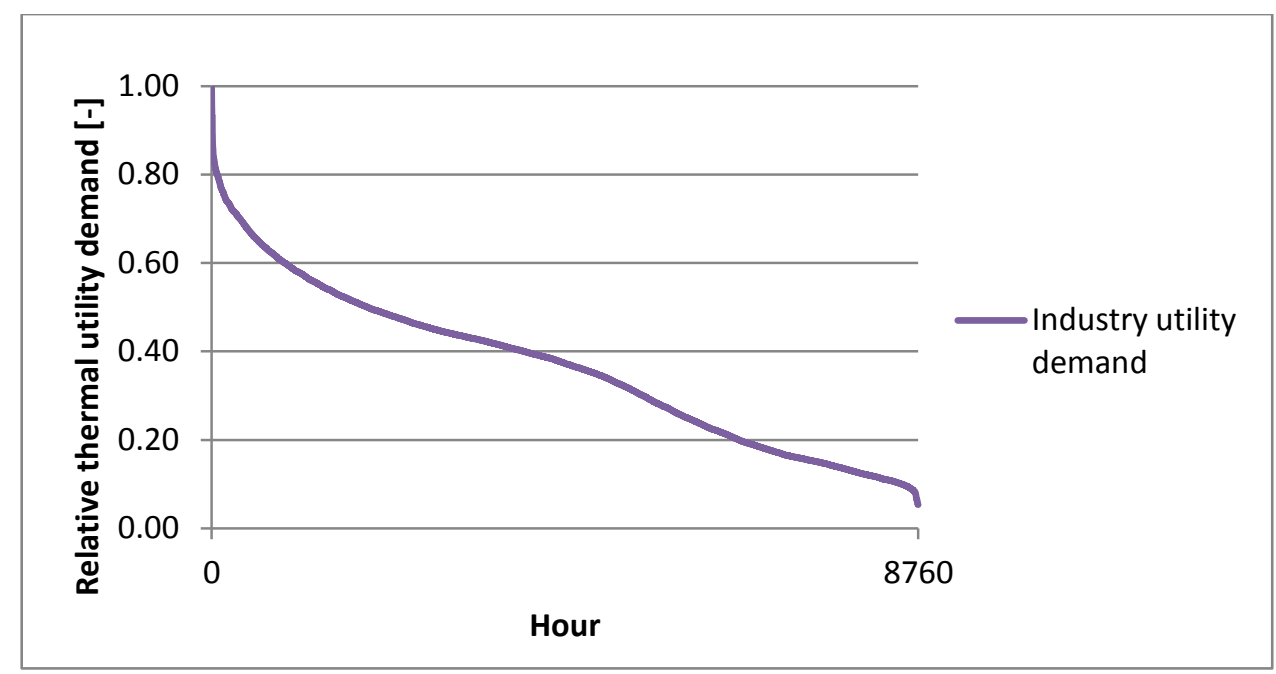

Figure 9: Relative industry thermal utility demand duration curve for one year.

As the system can be looked upon as replacing an existing district heating supply system and a reference industrial energy supply system, neither $\mathrm{CO}_{2}$ emission replacements nor incomes are associated with district heating and industry thermal utility generation. Instead, the resulting NPV and TCE of the FMG may be compared with those of the reference system to assess the performance of the retrofitted system.

Four additional scenarios were considered for assessing performance uncertainties of selected designs: A low fuel price scenario, in which the methanol selling price was reduced by $25 \%$ compared to the reference scenario; a high fuel price scenario, in which the methanol selling price was increased by $25 \%$ compared to the reference scenario; a NonFlex power scenario, in which power prices for 2035 were taken from the NonFlex scenario as described previously [43]. And a low power price scenario, in which power prices in 2035 has been reduced by a factor 7.5 as compared to the NonFlex scenario.

Regarding TCE calculations, average emissions from power generation in the Danish energy system were used to represent the emissions of consumed or generated electricity. For 2015, the average $\mathrm{CO}_{2}$ emission from power generation was set to $270 \mathrm{~kg} / \mathrm{MWh}$, while it was set to $112 \mathrm{~kg} / \mathrm{MWh}$ for 2025 and 2035 [42]. The $\mathrm{CO}_{2}$ emission associated with waste combustion was set to $37.0 \mathrm{~kg} / \mathrm{GJ}$ [44]. A $\mathrm{CO}_{2}$ emission of 57.0 $\mathrm{kg} / \mathrm{GJ}$ was associated with natural gas combustion, while methanol was assumed to replace gasoline with an energy ratio of $1: 1$ and thereby resulting in a $\mathrm{CO}_{2}$ emission reduction of $73.0 \mathrm{~kg} / \mathrm{GJ}$ [42]. The wood chips were assumed to be $\mathrm{CO}_{2}$ neutral in the study. 
In order to reduce computation time of the operation optimization, the external operating condition dataset was reduced using the Characteristic Operating Pattern (CHOP) method for data aggregation [30]. In short, the CHOP method is a visually-based aggregation method which clusters operating points with similar parameter values in representative data points called CHOP groups. The operation optimization is then conducted for the CHOP groups rather than for each operating point, significantly reducing the computational effort. The clustering principle is illustrated in Figure 10.

Initial dataset

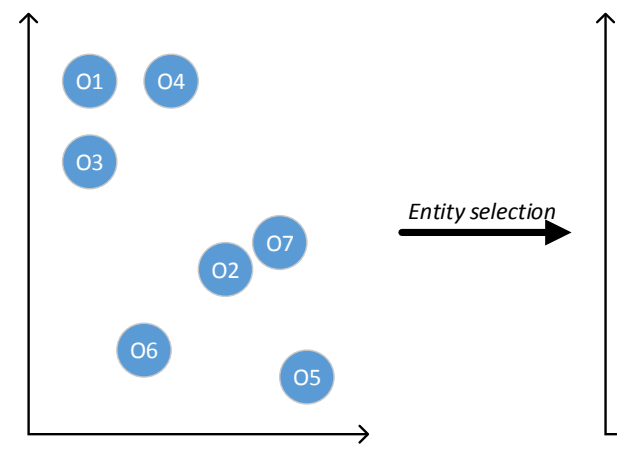

Clustering criteria

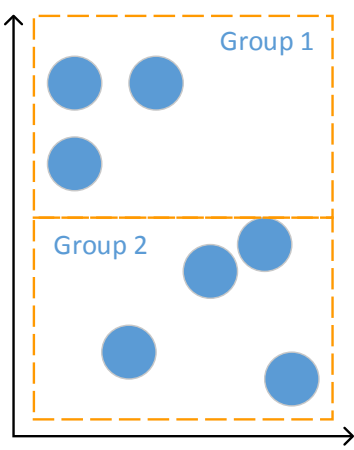

CHOP-reduced dataset

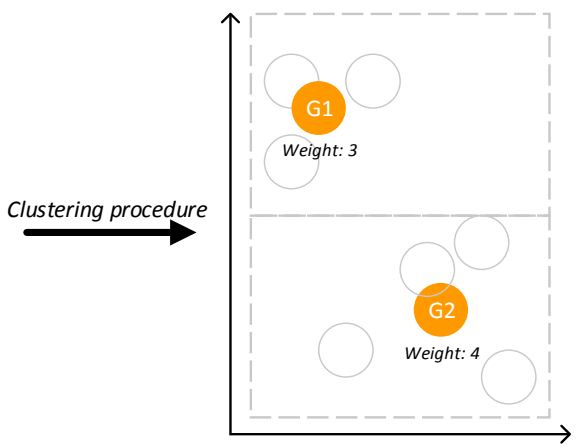

Figure 10: Principal sketch of the data aggregation principle applied in the CHOP method [30]. Operating points $O_{j}$ are clustered and merged into CHOP groups $G_{i}$ with aggregated weight factors.

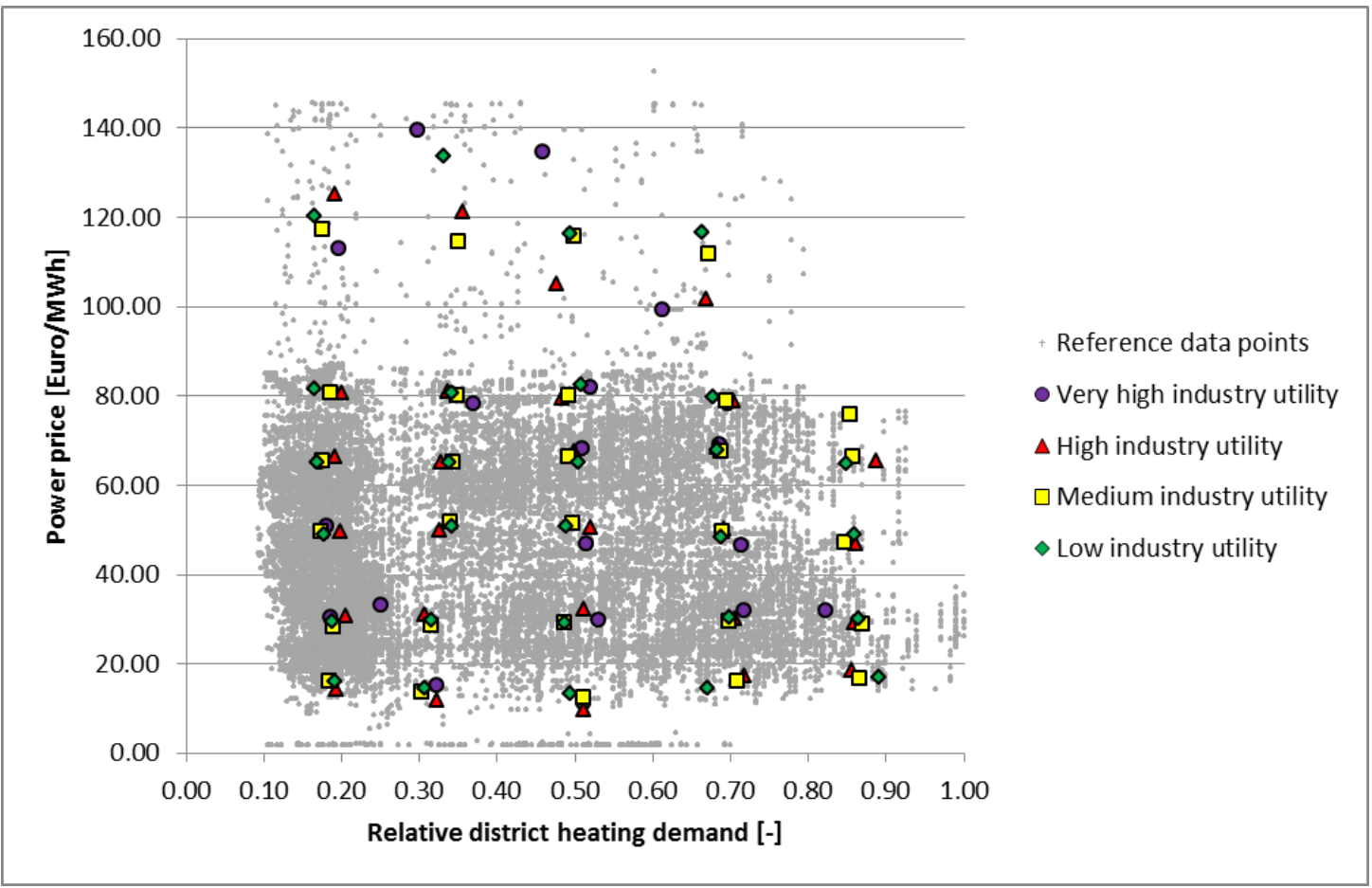

Figure 11: Scatter plot of the reference dataset and the aggregated dataset with respect to relative heating demand and power price. Note that the third dimension, industry utility demand, is not visible for the reference data points and that the duration (weight) of the aggregated points depends on the amount of reference points in their vicinity. For more information, refer to Appendix B.

In the present case, five volatile external operating conditions were identified using the CHOP approach: Power price, district heating demand, butchery thermal utility demand, wood chips price, and methanol price. Natural gas was not considered as a volatile external operating condition as the absolute variation 
within the scenario was less than $10 \%$. In order to minimize the number of CHOP groups to consider, data clustering was only conducted with respect to power price, district heating demand, and butchery thermal utility demand as they were the parameters with the largest volatility. The accuracy error of not clustering for methanol, natural gas, and wood chip prices was assessed a posteriori. The entire CHOP method procedure is described in Appendix $\mathrm{B}$, and the resulting $\mathrm{CHOP}$ datasets are presented for all scenarios as well. Reference operating points and resulting $\mathrm{CHOP}$ groups of the reference scenario are illustrated in Figure 11.

\subsection{Optimization model}

The system was optimized with respect to maximizing NPV and minimizing TCE over the period 2015-2035. Design variables for the optimization model are summarized in Error! Reference source not found., while operation variables are summarized in Table 9.

Table 8: Design variables in the case study optimization problem.

\begin{tabular}{|l|c|l|l|l|}
\hline Design variable & Notation & Type & Lower bound & Upper bound \\
\hline Biorefinery dimension [MWth biomass] & $\sigma_{\text {bio }}$ & Continuous & $5.0 \mathrm{MWth}$ & $200.0 \mathrm{MWth}^{\mathrm{a}}$ \\
\hline Biorefinery location & $\omega_{\text {bio }}$ & \multicolumn{3}{|c|}{ Integer } \\
\hline Product gas connection between areas & $\omega_{\text {gas }}$ & \multicolumn{3}{|c|}{ Integer } \\
\hline District heating integration at butchery & $\omega_{D H}$ & \multicolumn{3}{|c|}{ Integer } \\
\hline
\end{tabular}

a: The upper bound of $200 \mathrm{MWTh}$ corresponds to a medium-sized methanol-producing biorefinery based on the selected technology [34], and it is estimated that larger facilities cannot be accommodated on the site due to infrastructure constraints.

Table 9: Operation variables in the case study optimization problem.

\begin{tabular}{|l|c|l|l|l|}
\hline Horsens CHP operation variables & Notation & Type & Lower bound & Upper bound \\
\hline Rankine cycle load & $\lambda_{\text {an }}$ & Continuous & $0.75[31]$ & 1.00 \\
\hline Gas turbine load & $\lambda_{g t}$ & Continuous & $0.40^{\mathrm{a}}$ & 1.00 \\
\hline SOEC load & $\lambda_{S O E C}$ & Continuous & 0.00 & 1.00 \\
\hline Methanol production load & $\lambda_{M e O H}$ & Continuous & 0.00 & 1.00 \\
\hline Gas boiler load & $\lambda_{g b, i n d}$ & Continuous & 0.00 & 1.00 \\
\hline Industrial heat pump load & $\lambda_{h p, i n d}$ & Continuous & 0.00 & 1.00 \\
\hline
\end{tabular}

a: Minimum load constrained due to exhaust emission constraints [31].

The NPV, $C_{0}$, was calculated as a function of investments costs $C_{i n v, k}$ and hourly operation result $c_{o p, i}$ times the present value time factor $t_{P V, i}$ for each period $i$. The facility to be installed was given a lifetime of 20 years, and an interest rate of $r=0.05$ was applied in net present value calculations.

$C_{0}=-\sum_{k} C_{i n v, k}\left(\sigma_{k}, \omega_{k}\right)-\sum_{i} c_{o p, i}\left(\lambda_{i}\right) \cdot t_{P V, i}$

Investment costs for each facility was calculated as

$C_{i n v, k}\left(\sigma_{k}, \omega_{k}\right)=\omega_{k} C_{i n v, k 0}\left(\frac{\sigma_{k}}{\sigma_{k 0}}\right)^{p_{f}}$

Here, $C_{i n v, k 0}$ is the reference investment cost and $\sigma_{k 0}$ is the reference dimension of the facility. A power factor of $p_{f}=0.75$ was used for economy-of-scale calculations.

The present value time factor for each reference data point was calculated as 
463 Here, $T$ is the number of years from the installation of the FMG, and $t_{i}$ is the duration of the period.

464 The TCE, $Z_{0}$, was calculated as the sum of hourly emission results $z_{o p, i}$ for each period $i$ times the duration 465 of the period $t_{i}$.

$466 \quad Z_{0}=\sum_{i} z_{o p, i}\left(\lambda_{i}\right) \cdot t_{i}$

467

The hourly emission result $z_{o p, i}$ is calculated as the sum of emissions related to FMG operation minus the sum of emissions from replaced production.

$z_{\text {op }, i}\left(\boldsymbol{\lambda}_{\boldsymbol{i}}\right)=\sum_{i} z_{\text {emitted }, i}\left(\boldsymbol{\lambda}_{\boldsymbol{i}}\right)-\sum_{i} z_{\text {replaced }, i}\left(\boldsymbol{\lambda}_{\boldsymbol{i}}\right)$

Process integration was conducted for both areas. A pinch temperature of $10 \mathrm{~K}$ was used for integration of thermal streams, apart from in the condensers of the steam Rankine cycle where a pinch temperature of $3.5 \mathrm{~K}$ was used. The investment cost of the heat exchanger network was estimated for each assessed design as a part of the pinch analysis using a method from Turton et al. [45]. Further information can be found in Bolliger [46].

The optimization model to be solved in the case study can be written in condensed form as

$$
\left\{\begin{array}{c}
\min _{\omega_{k}, \sigma_{k}, \lambda_{k, i}}\left\{\begin{array}{l}
-C_{0} \\
Z_{0}
\end{array}\right. \\
\text { with variables } \\
\omega_{k} \in\{0,1\} \\
\sigma_{k} \in\left[\sigma_{k, \text { min }}, \sigma_{k, \text { max }}\right] \\
\lambda_{k, i} \in\left[\lambda_{k, \text { min }}, \lambda_{k, \text { max }}\right]
\end{array}\right.
$$

The problem (6) was solved using the hybrid genetic algorithm/mixed integer-linear programming approach as described in Lythcke-Jørgensen et al. [6]. The genetic algorithm was run for 6 generations with a population size of 20 .

\section{Results}

\subsection{Design optimization}

Running the optimization procedure for (6), a database of optimized design solutions was obtained. Figure 12 presents a scatter plot illustrating the performances of optimized solutions with respect to NPV and TCE.

First of all, the figure illustrates that under the set conditions and assumptions, there is no trade-off between reducing TCE and maximizing NPV for the FMG designs. This outcome suggests that the biorefinery is competitive for the price schemes considered, and that the upper bound on NPV is defined by the constraint on the biorefinery dimension for the given site. It must be emphasized that taxes, subsidies and similar aspects were not considered in the economic calculations. 
Regarding environmental impact, it was found that the larger the biorefinery dimension, the lower the TCE. In addition, most of the proposed designs obtain a negative TCE, suggesting that energy generation in these designs would replace generation with higher specific $\mathrm{CO}_{2}$ emission levels in the reference energy system. Secondly, it was found that designs having the biorefinery located next to the local industry (Scenario B) performed better with respect to both objectives than designs where the biorefinery was located next to the CHP unit (retrofit scenario A). This was primarily due to integration synergies, as a part of the reference natural gas consumption of the butchery could be replaced by process heat and unreacted product gas from the biorefinery. In Scenario $A$, the same replacement of natural gas consumption in the butchery required investments in district heating and gas infrastructure and industrial heat pumps. However, the overall synergy benefits only resulted in a few percent increase NPV and similar reduction in TCE for similar biorefinery dimensions, meaning that impacts from synergies were only marginal compared to the overall impact of installing a large-scale biorefinery.

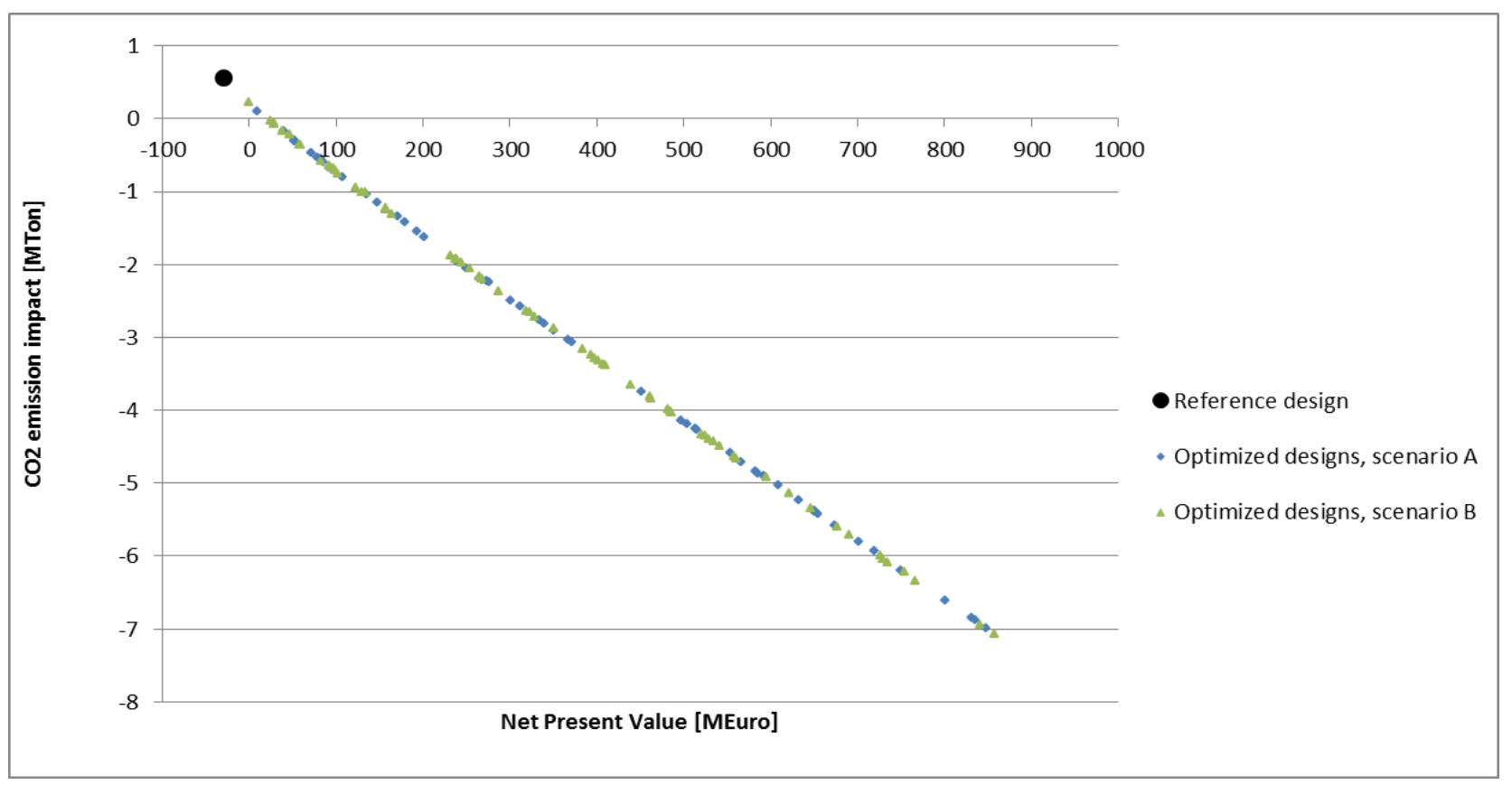

Figure 12: Scatter plot of optimized design solutions with respect to NPV and TCE. 


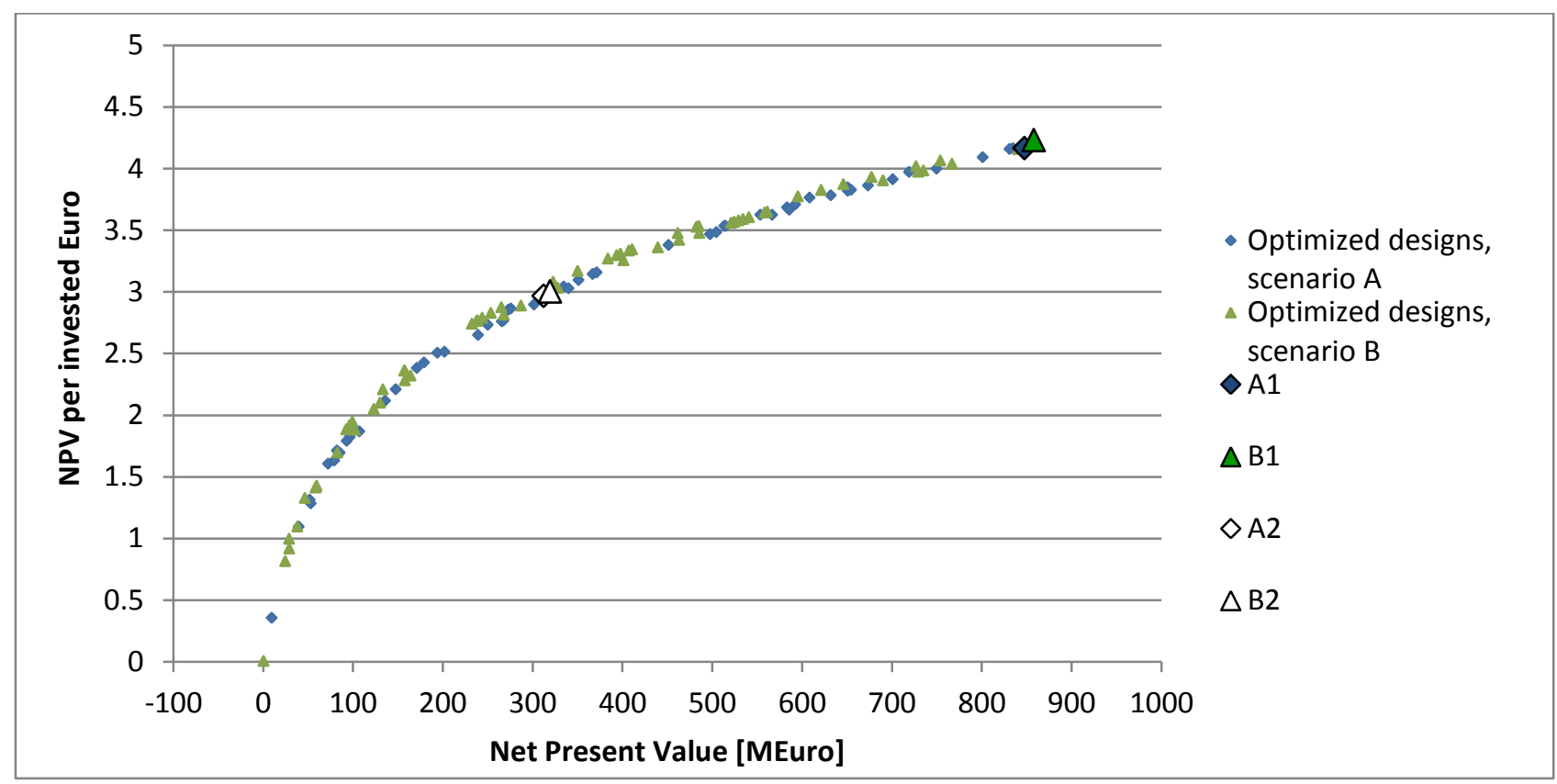

Figure 13: Scatter plot of optimized design solutions with respect to NPV and TCE.

In addition, the end results are found to have an almost linear profile, suggesting that nonlinear impacts from economy-of-scale in investments have little impact on the overall results when compared to linear operation impacts. The importance of various input parameters and associated performance uncertainties are assessed in the next section. However, it must be stressed that in the present study, district heating and industry utility services were included as constraints that had to be met, and economic benefits of meeting them were neglected. In case fixed costs were considered for these services, it would have a fixed positive impact on all NPVs. In addition, if costs were considered for cooling excess process heat were considered, this would have a negative impact for designs with larger biorefinery dimensions. Together, these effects would perhaps improve the significance of process integration benefits in the case study, which may in fact lead to a trade-off between economy-of-scale and process integration benefits.

Investigating the benefits of investments, a plot illustrating the relation between NPV and NPV per invested Euro is presented in Figure 14. The plot illustrates how the relative payback on investments increases with increasing NPV, and thereby biorefinery dimension. It is also found that relative investment payback in general is a few percent higher for retrofit scenario $B$ than for retrofit scenario $A$.

\subsection{Uncertainty analysis}

Four optimized designs were selected for uncertainty analysis: The two retrofit designs with the highest NPV for both retrofit scenarios (A1 and B1), and two optimized designs with a biorefinery dimension of approximately $80.0 \mathrm{MWth}$ (A2 and B2), representing medium-scaled design solutions. Design and performance characteristics of the selected designs are summarized in Table 10.

Table 10: Design and performance characteristics of the four selected FMG designs.

\begin{tabular}{|l|l|l|c|l|l|}
\hline Design solution & NPV [M€] & CO $_{2}$ emission impact [MTon] & $\sigma_{\text {bio }}$ & $\omega_{\text {DH }}$ & $\omega_{\text {gas }}$ \\
\hline A1 & 847.3 & -6.98 & 199.3 & 0 & 1 \\
\hline A2 & 312.0 & -2.57 & 81.2 & 1 & 0 \\
\hline
\end{tabular}




\begin{tabular}{|l|l|l|l|l|l|}
\hline B1 & 857.6 & -7.07 & 199.9 & 0 & 0 \\
\hline B2 & 319.0 & -2.63 & 82.4 & 1 & 0 \\
\hline
\end{tabular}

Table 11: Input parameter uncertainties considered in the investment cost uncertainty analysis.

\begin{tabular}{|l|c|l|l|l|}
\hline Parameter & Notation & Minimum value & Maximum value & Distribution \\
\hline $\begin{array}{l}\text { Biorefinery reference } \\
\text { investment cost }\end{array}$ & $C_{i n v, b i o 0}$ & $236.18 \mathrm{M} €$ & $393.63 \mathrm{M} €$ & Uniform \\
\hline $\begin{array}{l}\text { District heating connection, } \\
\text { investment cost }\end{array}$ & $C_{i n v, D H}$ & $1.31 \mathrm{M} €$ & $2.19 \mathrm{M} €$ & Uniform \\
\hline $\begin{array}{l}\text { Gas infrastructure, } \\
\text { investment cost }\end{array}$ & $C_{i n v, g a s}$ & $0.88 \mathrm{M} €$ & $1.46 \mathrm{M} €$ & Uniform \\
\hline $\begin{array}{l}\text { Heat pump reference } \\
\text { investment cost }\end{array}$ & $C_{i n v, h p 0}$ & $0.32 \mathrm{M} €$ & $0.54 \mathrm{M} €$ & Uniform \\
\hline Power factor & $p_{f}$ & 0.6 & 0.9 & Uniform \\
\hline
\end{tabular}

Variations in estimated NPV from uncertainties in investment costs and economy-of-scale benefits were assessed by applying the Monte Carlo simulation procedure presented by Sin et al. [47]. Reference investment costs were given a uniform uncertainty in the interval of $\pm 25 \%$, while the power factor $p_{f}$ was given a uniform uncertainty in the interval $\pm 20 \%$. An overview of the uncertainties associated with various input parameters is given in Table 11.

For each Monte Carlo simulation, a sample of 1000 data points was generated using Latin Hypercube Sampling [48] and assuming zero correlation between uncertainties in input parameters. Running Monte Carlo simulations for all selected designs, the resulting $10^{\text {th }}$ to $90^{\text {th }}$ percentile intervals of predicted NPV for the designs are shown in Figure 14.

The results suggest that the considered uncertainties for investment costs would lead to NPV variations of $\pm 7 \%$. Absolute variations in NPV were larger for designs A1 and B1, which was expected as absolute investment costs were higher for these designs. The outcomes illustrate that the investment uncertainties considered are not likely to have a significant influence on the overall performance of the designed FMGs over the 20 year period. 


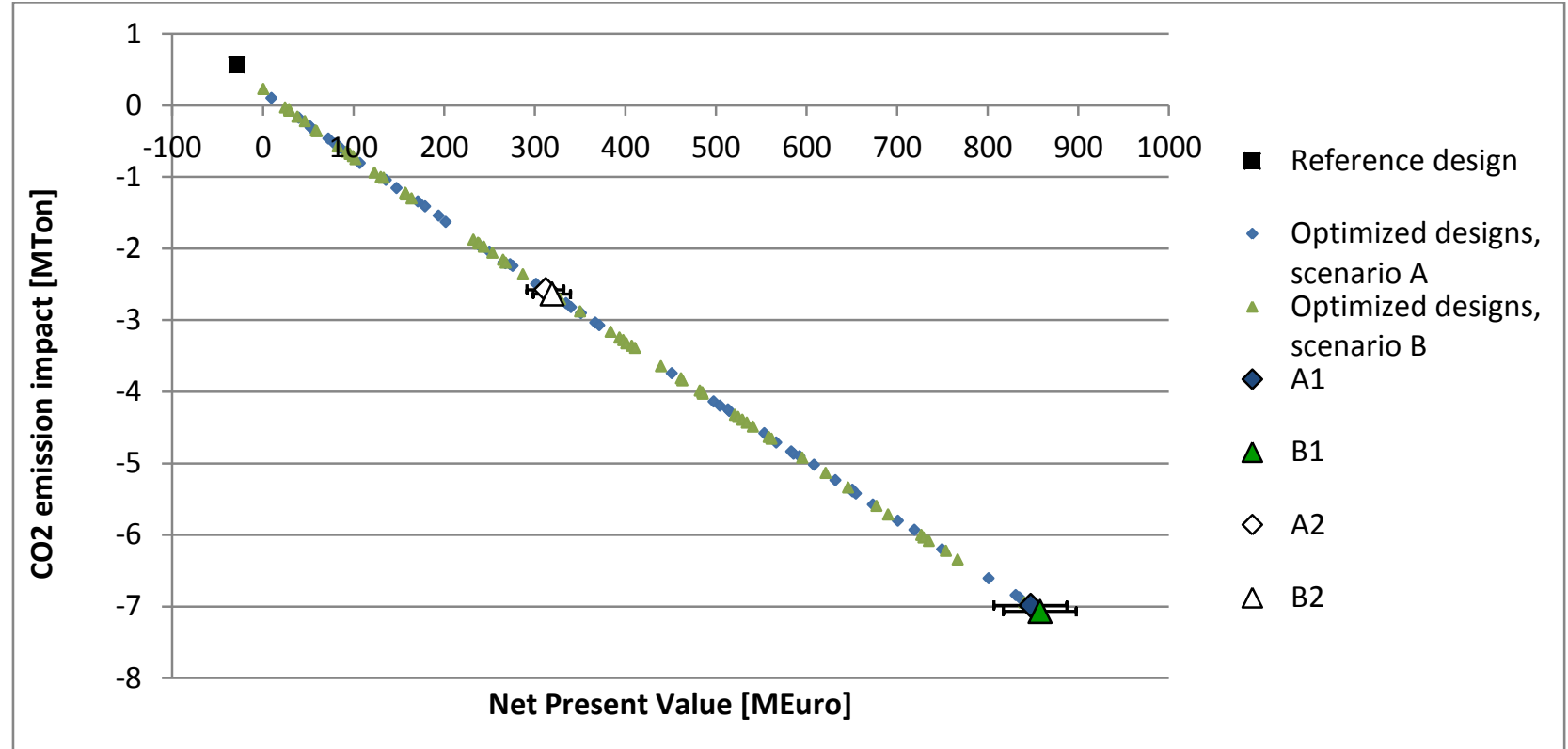

Figure 14: Selected designs and associated $10^{\text {th }}$ to $90^{\text {th }}$ percentile NPV performance variability in response to the investment cost uncertainties described in Table 11.

543 In addition to the uncertainty related to investment costs, the impact of changes in the interest rate 544 applied in the NPV calculations was assessed. For each of the four selected designs, the operation optimization was conducted using an interest rate of $20 \%$ instead of the $5 \%$ to represent a high interest rate which could be expected in a private economic business case. The results, including $10^{\text {th }}$ to $90^{\text {th }}$ percentile intervals of predicted NPV based on investment cost uncertainties, are shown in Figure 15.

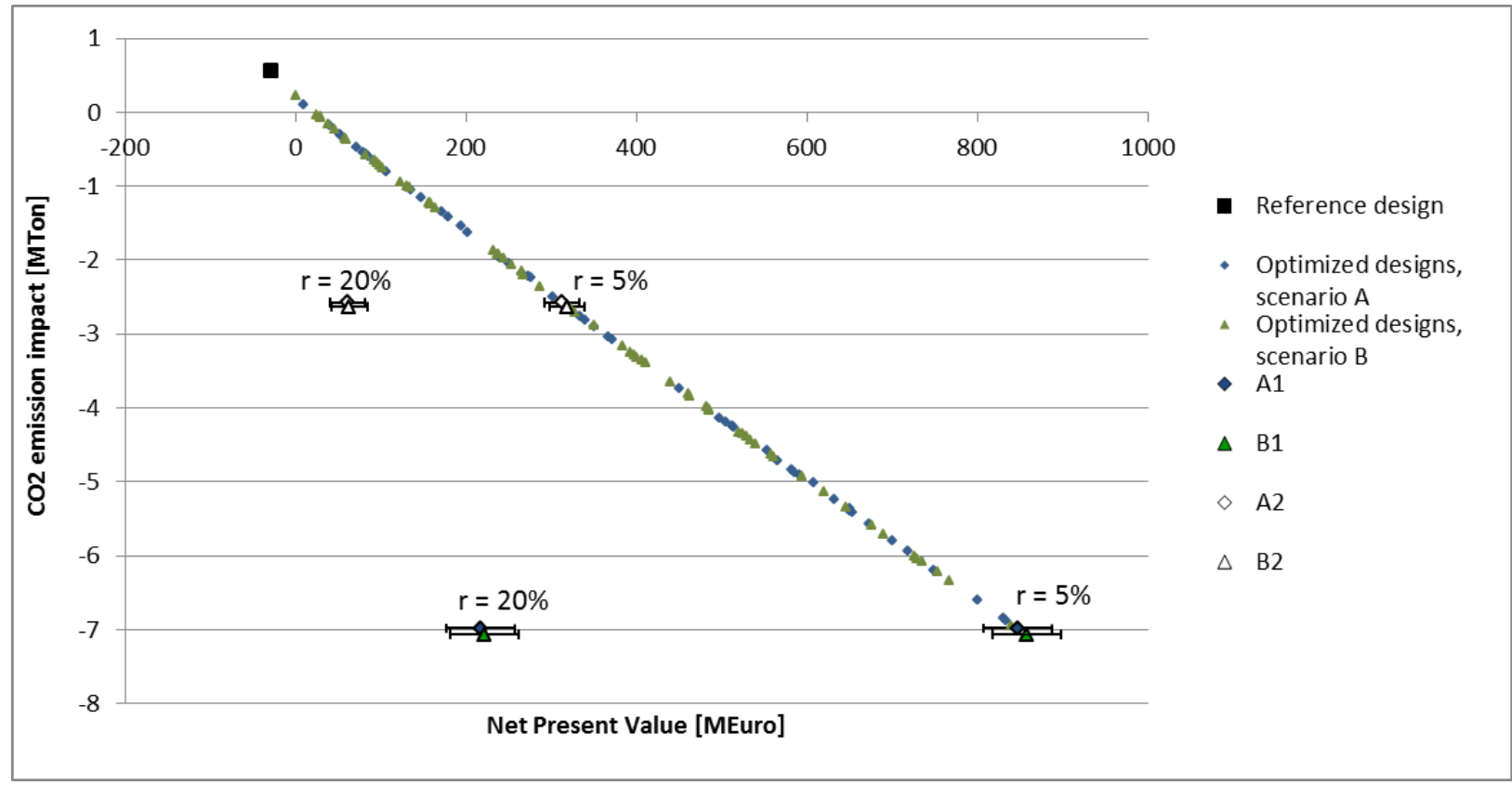

Figure 15: Performance of the four selected designs, including uncertainties related to investment costs, when changing the applied interest rate from $5 \%$ to $20 \%$

551 The NPV was found to be reduced by $74 \%-80 \%$ for the four selected designs when the interest rate was 552 increased to $20 \%$, which was expected as an interest rate of $20 \%$ would make it much less attractive to 
553 invest in the project when compared to a situation with an interest rate of $5 \%$. Uncertainties related to the 554 applied interest rate are therefore likely to have a markedly higher impact on the NPV than the assumed 555 uncertainties related to investment costs.

556 Another interesting outcome is the finding that the uncertainties related to investment costs will have a 557 relatively larger impact on the NPV uncertainty for larger interest rates. This is because investment costs 558 are unaffected by the interest rate in NPV calculations, meaning that the absolute impact is constant while 559 the overall NPV is reduced for larger interest rates. Hence, the larger the interest rate, the larger the 560 relative impact of uncertainties in investment costs.

561 In order to assess the impact of uncertain operating conditions, the performances of the four selected 562 designs were assessed for each of the four additional energy system scenarios defined in Section 2.4: A high 563 fuel price scenario, a low fuel price scenario, the Nonflex scenario, and a low power price scenario. The 564 outcomes are illustrated in Figure 16.

565 From the figure, it is evident that methanol price uncertainties considered had a much higher influence on 566 NPV than uncertainties in investment costs. An increase of $25 \%$ in methanol price in the high fuel price 567 scenario increased the NPVs of the four selected designs by $67 \%-75 \%$, while a similar reduction in methanol 568 price of $25 \%$ in the low fuel price scenario resulted in NPV reductions of $66 \%-74 \%$. Also the low power price 569 570 571 scenario was found to have a larger impact on NPV variations than the considered uncertainties in investment costs. Opposed to this, changes in NPV from the NonFlex scenario were comparable with expected variations from investment cost uncertainties.

In addition, the TCE was found to increase in the low fuel price and NonFlex scenarios for all designs, owing to the fact that the power-to-methanol price ratio was increased, making SOEC operation uncompetitive in some periods. In consequence, hydrogen-boosted SOEC operation was terminated approximately $21 \%$ of the time in the low fuel price scenario, while it was terminated for a bit more than $4 \%$ of the time in the NonFlex scenario. Opposed to this, the TCE was only marginally affected in the high fuel price and low power price scenarios as the SOEC was already operated in hydrogen-boosted mode for more than $98 \%$ of 579 the time in the reference scenario, meaning that the potential of increasing methanol production was very limited. 

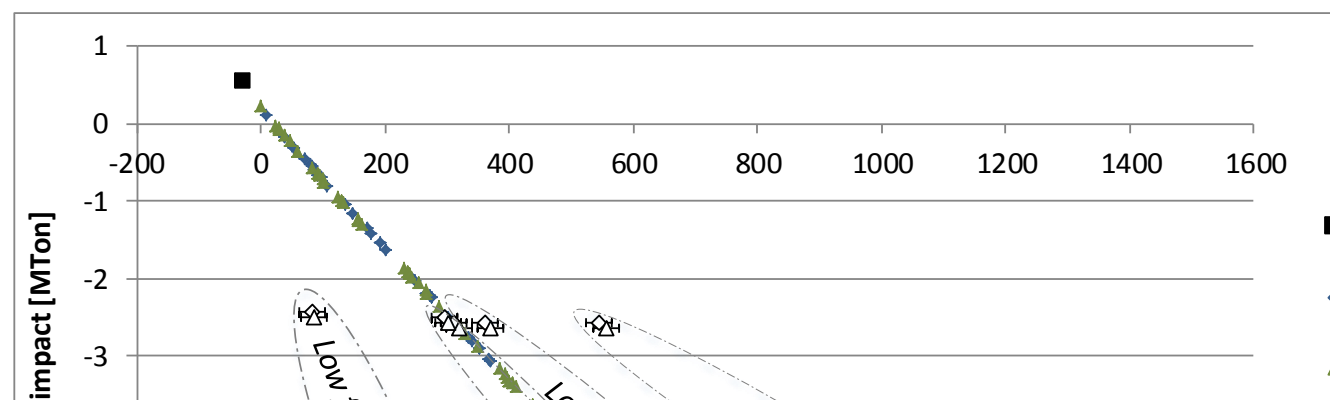

- Reference design

- Optimized designs, scenario A

- Optimized designs, scenario B

$\diamond \mathrm{A} 1$

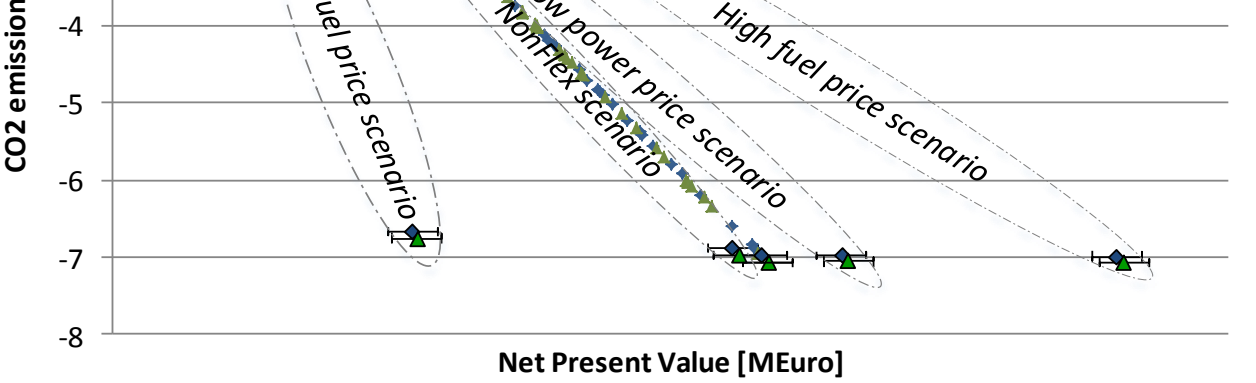

B1

$\diamond \mathrm{A} 2$

Figure 16: Performance of the four selected designs under various energy system scenarios. Results of the investment cost uncertainty analysis are indicated as well.

For the NonFlex scenario, the NPV was slightly reduced for all designs. This was caused by the higher power prices over the last six years for this scenario, which increased the costs of SOEC operation and thereby reduced the income from methanol sales.

To summarize, changes of $\pm 25 \%$ in the methanol price were found to have a major impact on the estimated performances of the FMGs in the case treated. The NPV of the optimal design solution, design B1, was estimated to vary within the range 252.5 M€ to $1471.6 \mathrm{M} €$ in response to the assessed input uncertainties on investment costs and operating conditions. Changing the interest to $20 \%$, the lowest estimated NPV of the design in the reference scenario was as low as $181.3 \mathrm{M} €$. For the optimal mediumsized design, design B2, the relative NPV variation was found to be even larger. In general, the outcomes stress the importance of including uncertainty analysis when designing and optimizing FMG concepts.

Finally, the maximum error made by averaging the prices of wood chips, methanol and natural gas in the CHOP-reduced dataset was estimated for design B1. Two additional simulations were conducted: One for a scenario where fuel prices in all hours were set to the maximum fuel price expected over the period, see Table 7, and one where the fuel prices in all hours were set to the minimum fuel price expected. The NPV result was reduced with $0.3 \mathrm{M} €$, or $0.03 \%$, when fuel prices were set to the minimum expected values, while it was increased by $0.5 \mathrm{M} €$, or $0.06 \%$, when fuel prices were set to the maximum expected values. As these variations are considered negligible, especially in comparison to the other sources of uncertainty investigated, it is deemed acceptable to average the prices of wood chips, methanol and natural gas in the CHOP method for the present case.

\section{Discussion}

In addition to the outcomes presented and discussed in Section 3, a number of uncertainties were not accounted for in the analysis. These are shortly discussed below. 
First of all, the surrogate models do not represent all process integration opportunities available. The Rankine cycle is modelled as a single black box, not allowing for steam extraction within or between turbine stages, which could otherwise be beneficial in order to extract steam as close to the required temperature and pressure as possible and thereby minimizing exergy destruction of the heat transfer [23]. In addition, exhaust gases from the gas turbine could be used as heat source for the Rankine cycle rather than directly for district heating, thereby increasing the conversion efficiency further. Spare capacity in the waste incineration may also allow for combustion of unreacted product gas, providing an additional usage opportunity for this energy flow. In effect, the results of this study should, with respect to process integration synergies, be regarded as a rough and conservative estimate of synergy potentials.

Regarding TCE calculations, emissions associated with power generation and consumption may as well be regarded as conservative estimates as annually averaged power generation emissions were used. In practice, it is expected that the share of renewables in the power producer mix would be higher during periods of low power prices and lower during periods of high power prices. As the optimized FMG operation causes the system to increase the power consumption and reduce the power generation in periods with low power prices, and vice versa in periods with high power prices, it is expected that the consumed power on average will have lower marginal $\mathrm{CO}_{2}$ emissions while generated power is expected to replace production with higher marginal $\mathrm{CO}_{2}$ emissions. In effect, this trend would make the overall TCE of the optimized designs smaller than what is calculated. However, in order to verify these considerations, an assessment of the system impact from FMG operation needs to be conducted. This is recommended as a topic for future research.

Opposed to this, the assumption that the wood chips are $\mathrm{CO}_{2}$ neutral is optimistic as it implies an assumption of zero emissions associated with the cultivation, harvesting, storing and transportation of the biomass. In reality, it is expected that a certain level of $\mathrm{CO}_{2}$ emission will be associated with the consumption of wood pellets, especially if they are transported over significant distances. This impact would increase the TCE of the optimized designs in the case study.

With respect to the energy system data applied, data for three reference years was used to estimate a period of 20 years. As discussed in Section 3.2, uncertainties in operating conditions were found to have a significant impact on the estimated FMG performance. This suggests that more detailed energy system data should be used in future analyses of the system, and that it would be relevant to define additional likely energy system scenarios in order to assess performance variations in response to likely operating condition uncertainties further.

In terms of uncertainty analysis, it must be noted that the scenario analysis and interest rate uncertainties were treated separately in the present work in order to assess the impacts of each of these uncertainties in detail. In reality, combinations of these uncertainties may lead to larger performance variation spans than the ones identified.

In the present work, the CHOP method was used for aggregating energy system data. Though advantageous in several ways, the use of the CHOP method has some flaws, the largest being the fact that short-term thermal and product storages cannot be considered in the optimization. In order to investigate if benefits from operation shifting made possible by short-term storages would change the optimal design of the FMG 
concept, it would be relevant to conduct the full design optimization using at least one additional data aggregation method that allows for the inclusion of short-term storages.

Concerning the biorefinery, the two-stage gasifier was mathematically designed in the FMG to scale between $5-200 \mathrm{MW}_{\text {th }}$ input. As mentioned, the gasifier has only been scaled up to $1.5 \mathrm{MW}_{\text {th }}$ in practice and hence this projection is associated with some technological uncertainty. While regular downdraft gasifiers usually scale up to $1-5 \mathrm{MW}_{\text {th }}[49,50]$, the two separate reactors in the two-stage gasifier allow some degrees of freedom with regards to design. The gasification concept is therefore projected to scale well, with the main challenges being the downdraft char gasifier and the externally heated pyrolysis unit. Replacing these units with other more scalable reactors, such as updraft or fluid bed, could lead to an effective scaling of the concept. For instance, Bentzen et al. [51] constructed an alternative and more scalable version of the two-stage gasifier using two fluid beds for fuel processing. With activated carbon at room temperature as the only downstream gas cleaning unit, a high gas quality was obtained with negligible tar levels.

Regarding the SOEC, the dimensioning was done a priori based on the largest feasible hydrogen addition in the methanol synthesis. It was found that the full SOEC capacity was utilized for more than $98 \%$ of the time in the reference scenario. However, in the design optimization the SOEC was by default installed in the biorefinery. With the prices of wood chips and power considered, wood chips is almost always a cheaper resource than power, making it economically attractive to increase the dimension of the gasifier rather than investing in SOEC capacity for hydrogen-boosted methanol production. Hence, under the given economic circumstances, hydrogen boosted methanol production is only considered attractive if wood chip availability is limited, questioning if an SOEC with capacity for maximum hydrogen production should be installed by default. Optimizing the dimension of the SOEC with respect to investment and operating pattern would be a relevant topic for future research.

For the low fuel price scenario, the SOEC was operated in full capacity when power prices were below 66 $€ / M W h$, equalling $79.0 \%$ of the operation duration. The SOEC was operated in oxygen-boosted mode for power prices in the range $66 € / \mathrm{MWh}$ to $122 € / \mathrm{MWh}$, approximately $20.9 \%$ of the time, while it was shut down the last $0.1 \%$ of the time when power prices exceeded $122 € / M W h$. Here, it could be relevant to investigate the impact of including oxygen storage, which could allow the SOEC to be shut down for the $21 \%$ of the time where the power price is too high for operation in hydrogen-boosted mode. If feasible, it could as well be considered if the SOEC operation could be inverted to make it run as a fuel cell on syngas during periods of high power prices. If so, the SOEC could be used for storing electricity as methanol, and then converting it to electricity when demands and prices are high, thereby extending the electricity system balancing from the FMG. The possibility of running the SOEC as a fuel cell may as well serve as an option for reducing the economic risk of low fuel prices for the overall FMG.

Finally, the middle estimated value of $\mathrm{CO}_{2}$ emission quotas from ref. [42] was included in the methanol price applied in the study. Over the period considered, the $\mathrm{CO}_{2}$ emission quota value accounted for between $2.5 \%$ and $11.5 \%$ of the methanol price depending on the year. In case the conservative estimate of $\mathrm{CO}_{2}$ emission quota value from ref. [42] had been used, the methanol price would have dropped between $0.7 \%$ and $4.4 \%$ over the period, while the optimistic estimate would have let to increases in methanol price of $0.0 \%$ to $4.5 \%$. Such variations would have a noticeable impact on NPVs of the designs, but the impact would fall within the NPV variation boundaries set by the $\pm 25 \%$ change in methanol price that was assessed as part of the uncertainty analysis. 


\section{Conclusion}

The present study treated the development of a flexible multi-generation system (FMG) which integrated a methanol-producing biorefinery with an existing CHP unit and industrial energy utility supply. Applying a previously developed design methodology, the FMG was modelled and its design optimized with respect to a 20-year system lifetime. Design aspects considered include: Process selection, dimensioning, location and integration; operation optimization considering hourly variations in operating conditions over the year as well as expected long term energy system development; and uncertainty analysis considering both investment costs and operating conditions.

Solving the design optimization for the reference scenario, the outcomes suggest that the optimal design with respect to both economic and environmental performance involved a maximum-sized biorefinery located next to the local industry. As the local industry energy demands were limited when compared to the biorefinery dimensions considered, process integration synergies were found to be marginal when compared to the economic and environmental impact of the biorefinery. The results further indicated that uncertainties in operating conditions, especially methanol price, would have a much higher impact on the performance of the designs than corresponding uncertainties in investment costs.

For the optimized design, the net present value (NPV) was estimated to vary within the range $252.5 \mathrm{M} €$ to 1471.6 M€ in response to parameter value changes of $\pm 25 \%$ of investments costs and methanol price. In addition, a change in the applied interest rate from $5 \%$ to $20 \%$ in the reference scenario would reduce the NPV to 181.3 M€. These significant variations in NPVs stress the importance of including systematic uncertainty analysis in the design optimization of FMG concepts.

\section{Acknowledgements}

The authors would like to acknowledge DONG Energy, Energinet.dk, and the Innovation Foundation through the 4DH project for their financial support of the research.

\section{References}

[1] Lund H. Renewable Energy Systems: The Choice and Modeling of $100 \%$ Renewable Solutions. Academic Press publications; 2010.

[2] Lund H, Andersen AN, Østergaard PA, Mathiesen BV, Connolly D. From electricity smart grids to smart energy systems - A market operation based approach and understanding. Energy 2012;42:96-102. doi:10.1016/j.energy.2012.04.003.

[3] Mathiesen BV, Lund H, Connolly D, Wenzel H, Østergaard P a., Möller B, et al. Smart Energy Systems for coherent 100\% renewable energy and transport solutions. Appl Energy 2015;145:139-54. doi:10.1016/j.apenergy.2015.01.075.

[4] DTU. DTU International Energy Report 2015 : Energy systems integration for the transition to non-fossil energy systems (http://www.natlab.dtu.dk/english/Energy_Reports/DIER-2015). 2015.

[5] Gassner M, Maréchal F. Thermo-economic optimisation of the polygeneration of synthetic natural gas (SNG), power and heat from lignocellulosic biomass by gasification and methanation. Energy Environ Sci 2012;5:5768. doi:10.1039/c1ee02867g.

[6] Lythcke-Jørgensen C, Ensinas A V., Münster M, Haglind F. A methodology for designing flexible multi-generation systems (in press). Energy 2016:1-21.

[7] Liu P, Pistikopoulos EN, Li Z. Polygeneration Systems Engineering. Process Syst. Eng., vol. 5, 2011, p. 1-38. doi:10.1002/9783527631292.ch1.

[8] Chicco G, Mancarella P. Distributed multi-generation: A comprehensive view. Renew Sustain Energy Rev 2009;13:535-51. doi:10.1016/j.rser.2007.11.014.

[9] Liu P, Pistikopoulos EN, Li Z. Decomposition Based Stochastic Programming Approach for Polygeneration Energy Systems 
Design under Uncertainty. Ind Eng Chem Res 2010;49:3295-305. doi:10.1021/ie901490g.

[10] Maréchal F, Weber C, Favrat D. Multiobjective Design and Optimization of Urban Energy Systems. Process Syst. Eng., 2011, p. 39-83. doi:10.1002/9783527631292.ch1.

[11] Fazlollahi S, Becker G, Maréchal F. Multi-objectives, multi-period optimization of district energy systems: I. Selection of typical operating periods. Comput Chem Eng 2014;65:54-66. doi:10.1016/j.compchemeng.2014.02.018.

[12] Fazlollahi S, Becker G, Maréchal F. Multi-objectives, multi-period optimization of district energy systems: II-Daily thermal storage. Comput Chem Eng 2014;71:648-62. doi:10.1016/j.compchemeng.2014.02.018.

[13] Fazlollahi S, Becker G, Maréchal F. Multi-objectives, multi-period optimization of district energy systems: III. Distribution networks. Comput Chem Eng 2014;66:82-97. doi:10.1016/j.compchemeng.2014.02.018.

[14] Sorknæs $P$, Lund $H$, Andersen AN. Future power market and sustainable energy solutions - The treatment of uncertainties in the daily operation of combined heat and power plants. Appl Energy 2015;144:129-38.

[15] Capuder T, Mancarella P. Techno-economic and environmental modelling and optimization of flexible distributed multigeneration options. Energy 2014;71:516-33. doi:10.1016/j.energy.2014.04.097.

[16] Capuder T, Mancarella P. Modelling and Assessment of the Techno-economic and Environmental Performance of Flexible Multi- Generation Systems. 18th Power Syst Comput Conf Wroclaw, Pol 2014.

[17] Martínez Ceseña E, Capuder T, Mancarella P. Flexible Distributed Multienergy Generation System Expansion Planning Under Uncertainty. IEEE Trans Smart Grid 2015:1-10. doi:10.1109/TSG.2015.2411392.

[18] Piacentino A, Barbaro C, Cardona F, Gallea R, Cardona E. A comprehensive tool for efficient design and operation of polygeneration-based energy micro-grids serving a cluster of buildings. Part I: Description of the method. Appl Energy 2013;111:1204-21. doi:10.1016/j.apenergy.2012.11.079.

[19] Zhou Z, Zhang J, Liu P, Li Z, Georgiadis MC, Pistikopoulos EN. A two-stage stochastic programming model for the optimal design of distributed energy systems. Appl Energy 2013;103:135-44. doi:10.1016/j.apenergy.2012.09.019.

[20] Rubio-Maya C, Uche-Marcuello J, Martínez-Gracia A, Bayod-Rújula A a. Design optimization of a polygeneration plant fuelled by natural gas and renewable energy sources. Appl Energy 2011;88:449-57. doi:10.1016/j.apenergy.2010.07.009.

[21] Chen Y, Adams TA, Barton PI. Optimal design and operation of flexible energy polygeneration systems. Ind Eng Chem Res 2011;50:4553-66. doi:10.1021/ie1021267.

[22] Lythcke-Jørgensen C, Haglind F, Clausen LR. Thermodynamic and Economic Analysis of Integrating Lignocellulosic Bioethanol, Copenhagen, Denmark: European Biomass Conference and Exhibition; 2013, p. 1-8.

[23] Lythcke-Jørgensen C, Haglind F, Clausen LR. Exergy analysis of a combined heat and power plant with integrated lignocellulosic ethanol production. Energy Convers Manag 2014;85:817-27. doi:10.1016/j.enconman.2014.01.018.

[24] Lythcke-Jørgensen C, Haglind F. Design optimization of a polygeneration plant producing power, heat, and lignocellulosic ethanol. Energy Convers Manag 2015;91:353-66. doi:10.1016/j.enconman.2014.12.028.

[25] Lythcke-Jørgensen C, Münster M, Ensinas A V, Haglind F. Design optimization of flexible biomass-processing polygeneration plants using characteristic operation periods. World Renew. Energy Congr. XIII, London: 2014.

[26] Danmarks Statistik 2014. http://www.statistikbanken.dk/.

[27] Thiessen K. Fjernvarme Horsens (personal contact) 2015. fjho.dk.

[28] Clausen LR, Elmegaard B, Ahrenfeldt J, Henriksen U. Thermodynamic analysis of small-scale dimethyl ether (DME) and methanol plants based on the efficient two-stage gasifier. Energy 2011;36:5805-14. doi:10.1016/j.energy.2011.08.047.

[29] Clausen LR. Maximizing biofuel production in a thermochemical biorefinery by adding electrolytic hydrogen and by integrating torrefaction with entrained flow gasification. Energy 2015;85:94-104. doi:10.1016/j.energy.2015.03.089.

[30] Lythcke-Jørgensen C, Haglind F, Ensinas A V., Münster M. A method for aggregating external operating conditions in multigeneration plant optimization models. Appl Energy 2016:59-75. doi:10.1016/j.apenergy.2015.12.050.

[31] Energistyrelsen, Energinet.dk. Technology Data for Energy Plants - Generation of Electricity and District Heating, Energy Storage and Energy Carrier Generation and Conversion 2015:1-220. doi:ISBN: 978-87-7844-940-5.

[32] Ahrenfeldt J, Henriksen U, Jensen TK, G??bel B, Wiese L, Kather A, et al. Validation of a continuous combined heat and power (CHP) operation of a two-stage biomass gasifier. Energy and Fuels 2006;20:2672-80. doi:10.1021/ef0503616.

[33] Ahrenfeldt J, Thomsen TP, Henriksen U, Clausen LR. Biomass gasification cogeneration - A review of state of the art technology and near future perspectives. Appl Therm Eng 2013;50:1407-17. doi:10.1016/j.applthermaleng.2011.12.040.

[34] Evald A, Hu G, Hansen MT. Technology data for advanced bioenergy fuels. 2013.

[35] Vad Mathiesen B, Ridjan I. Technology Data for High Temperature Solid Oxide Electrolyser Cells, Alkali and Pem Electrolysers. Aalborg, Denmark: 2013.

[36] Jensen JK, Ommen T, Markussen WB, Reinholdt L, Elmegaard B. Technical and economic working domains of industrial 
heat pumps: Part 2 - Ammonia-water hybrid absorption-compression heat pumps. Int J Refrig 2014;55:183-200.

[37] Dansk Fjernvarme. Temamøde om landsbynærvarme 2015. http://www.danskfjernvarme.dk/kurser-ogmoeder/moedematerialer/2014-25-marts-temamoede-om-landsbynaerva (accessed March 31, 2016).

[38] Energiforskning.dk. Analyser for kommercialisering af brintteknologier n.d. http://www.energiforskning.dk/da/project/analyser-kommercialisering-af-brintteknologier (accessed March 15, 2016). Danish Energy Agency. FORUDS/ETNINGER FOR SAMFUNDSøKONOMISKE ANALYSER PÅ ENERGIOMRÅDET. 2014.

[40] Danish Energy Agency. Oliepriser 2016. http://www.ens.dk/info/tal-kort/statistik-nogletal/energipriser-afgifter/oliepriser (accessed March 29, 2016).

[41] Energinet.dk. SIFRE: Simulation of Flexible and Renewable Energy sources (http://energinet.dk/SiteCollectionDocuments/Danske\%20dokumenter/El/sifre_fall2015.pdf). 2015.

[42] Energinet.dk. Energinet.dk's analyseforudsætninger 2012-2035. 2012.

[43] Energinet.dk, Dansk Energi. Smart Energy - hovedrapport (http://energinet.dk/DA/KLIMA-OGMILJOE/Energianalyser/Analyser/Sider/Smart-Energy.aspx) 2015.

[44] Energistyrelsen. Energistatistik 2014 - Data, tabeller, statistikker og kort. 2015.

[45] Turton R, Bailie RC, Whiting WB, Shaeiwitz J a. Analysis, Synthesis, and Design of Chemical Processes. 1998.

[46] Bolliger R. Méthodologie de la synthèse des systèmes énergétiques industriels. 2010. doi:10.5075/epfl-thesis-4867.

[47] Sin G, Gernaey K V., Lantz AE. Good modeling practice for PAT applications: Propagation of input uncertainty and sensitivity analysis. Biotechnol. Prog., vol. 25, 2009, p. 1043-53. doi:10.1002/btpr.166.

[48] McKay MD, Beckman RJ, Conover WJ. Comparison of three methods for selecting values of input variables in the analysis of output from a computer code. Technometrics 1979;21:239-45. doi:10.2307/1271432.

[49] Basu P. Biomass Gasification, Pyrolysis and Torrefaction. 2013. doi:10.1016/B978-0-12-396488-5.00013-7.

[50] Knoef H. Handbook Biomass Gasification. Biomass Gasification Group; 2005.

[51] Bentzen J, Hummelsh $\varnothing j$ R, Henriksen U. Upscale of the two-stage gasification process. Proc 2 World Conf Technol Exhib Biomass Energy Ind 2004;10-14 May,:1004-7.

[52] Adams TA, Ghouse JH. Polygeneration of fuels and chemicals. Curr Opin Chem Eng 2015;10:87-93. doi:10.1016/j.coche.2015.09.006. 


\section{Appendix A - System model data}

This appendix includes all mass and energy flow functions of the FMG system model.

Table 12: Thermal energy flow functions.

\begin{tabular}{|c|c|c|c|c|c|}
\hline Facility & Flow-description & Notation & Type & Function [MJ/s] & $T_{\text {in }} / T_{\text {out }}$ \\
\hline \multirow[t]{4}{*}{ Horsens CHP } & 0.8 bar condenser heat & $\dot{Q}_{r a n, h p}$ & Hot & $\lambda_{\text {ran }} \dot{Q}_{r a n, h p 0}$ & $93.5^{\circ} \mathrm{C} / 93.5^{\circ} \mathrm{C}$ \\
\hline & 0.3 bar condenser heat & $\dot{Q}_{\text {ran,lp }}$ & Hot & $\lambda_{\text {ran }} \dot{Q}_{r a n, l p 0}$ & $69.1^{\circ} \mathrm{C} / 69.1^{\circ} \mathrm{C}$ \\
\hline & Gas turbine, off gas heat & $\dot{Q}_{g t, o f f}$ & Hot & $\lambda_{g t} \sigma_{g t}\left(\eta_{g t}-\eta_{g t, P}\right)$ & $600^{\circ} \mathrm{C} / 70^{\circ} \mathrm{C}$ \\
\hline & District heating generation & $\dot{Q}_{d h}$ & Cold & $\sigma_{d h} \lambda_{d h}$ & $40^{\circ} \mathrm{C} / 90^{\circ} \mathrm{C}$ \\
\hline \multirow[t]{4}{*}{ Butchery } & Room heating and losses & $\dot{Q}_{\text {ind,room }}$ & Cold & $0.24 \cdot \sigma_{\text {ind }} \lambda_{\text {ind }}$ & $35^{\circ} \mathrm{C} / 35^{\circ} \mathrm{C}$ \\
\hline & Cleaning & $\dot{Q}_{\text {ind,cl }}$ & Cold & $0.37 \cdot \sigma_{\text {ind }} \lambda_{\text {ind }}$ & \\
\hline & Boiling and evaporation & $\dot{Q}_{\text {ind,ev }}$ & Cold & $0.04 \cdot \sigma_{\text {ind }} \lambda_{\text {ind }}$ & $110^{\circ} \mathrm{C} / 100^{\circ} \mathrm{C}$ \\
\hline & Gas boiler, off gas heat & $\dot{Q}_{g b, o f f}$ & Hot & $\sigma_{\text {ind }} \lambda_{\text {gb,ind }}$ & $1000^{\circ} \mathrm{C} / 70^{\circ} \mathrm{C}$ \\
\hline \multirow[t]{2}{*}{$\begin{array}{l}\text { Hybrid heat } \\
\text { pump }\end{array}$} & District heating source & $\dot{Q}_{h p, i n}$ & Cold & $\sigma_{h p} \lambda_{h p} \frac{C O P-1}{C O P}$ & $40^{\circ} \mathrm{C} / 90^{\circ} \mathrm{C}$ \\
\hline & Process heat sink & $\dot{Q}_{h p, \text { out }}$ & Hot & $\sigma_{h p} \lambda_{h p}$ & $120^{\circ} \mathrm{C} / 110^{\circ} \mathrm{C}$ \\
\hline \multirow[t]{10}{*}{ Biorefinery } & Gasifier, B & $\dot{Q}_{B}$ & Cold & $0.118 \cdot \sigma_{b i o}$ & $115^{\circ} \mathrm{C} / 200^{\circ} \mathrm{C}$ \\
\hline & Gasifier, C & $\dot{Q}_{C}$ & Hot & $0.020 \cdot \sigma_{\text {bio }}$ & $236^{\circ} \mathrm{C} / 127^{\circ} \mathrm{C}$ \\
\hline & Gasifier, D & $\dot{Q}_{D}$ & Hot & $0.062 \cdot \sigma_{\text {bio }}$ & $114^{\circ} \mathrm{C} / 40^{\circ} \mathrm{C}$ \\
\hline & Methanol, G & $\dot{Q}_{G}$ & Hot & $0.070 \cdot \sigma_{\text {bio }} \lambda_{\text {meth }}$ & $220^{\circ} \mathrm{C} / 220^{\circ} \mathrm{C}$ \\
\hline & Methanol, H & $\dot{Q}_{H}$ & Hot & $0.076 \cdot \sigma_{\text {bio }} \lambda_{\text {meth }}$ & $110^{\circ} \mathrm{C} / 40^{\circ} \mathrm{C}$ \\
\hline & Methanol, J & $\dot{Q}_{J}$ & Cold & $0.010 \cdot \sigma_{\text {bio }} \lambda_{\text {meth }}$ & $84^{\circ} \mathrm{C} / 84^{\circ} \mathrm{C}$ \\
\hline & Methanol, K & $\dot{Q}_{K}$ & Cold & $0.033 \cdot \sigma_{\text {bio }} \lambda_{\text {meth }}$ & $40^{\circ} \mathrm{C} / 110^{\circ} \mathrm{C}$ \\
\hline & Methanol, N & $\dot{Q}_{K}$ & Hot & $0.122 \cdot \sigma_{\text {bio }} \lambda_{\text {meth }}$ & $153^{\circ} \mathrm{C} / 40^{\circ} \mathrm{C}$ \\
\hline & SOEC excess heat & $\dot{Q}_{K}$ & Hot & 0.5 & $200^{\circ} \mathrm{C} / 40^{\circ} \mathrm{C}$ \\
\hline & Off-product gas burner & $\dot{Q}_{o f f}$ & Hot & $0.24 \cdot \sigma_{b i o} \cdot \lambda_{s b}$ & $600^{\circ} \mathrm{C} / 70^{\circ} \mathrm{C}$ \\
\hline
\end{tabular}

Table 13: Energy flow functions.

\begin{tabular}{|l|l|c|c|}
\hline \multicolumn{1}{|c|}{ Plow-description } & Notation & Function [MW] \\
\hline WOOD CHIPS FLOWS & $\dot{e}_{\text {wood chips }}$ & $\sigma_{\text {bio }}$ \\
\hline Biorefinery & Gasifier wood chip consumption & $P_{\text {ran }}$ & $7 \cdot \lambda_{\text {ran }}$ \\
\hline \\
POWER FLOWS & Power generation, Rankine & $P_{g t}$ & $8 \cdot \lambda_{\text {ran }}$ \\
\hline Horsens CHP & Power generation, gas turbine & $P_{h p}$ & $-\frac{\sigma_{h p} \lambda_{h p}}{C O P}$ \\
\hline & Ammonia-water hybrid heat pump & $P_{\text {meth }}$ & $0.096 \cdot \lambda_{\text {meth }} \sigma_{\text {bio }}$ \\
\hline Butchery & Methanol production power demand & $P_{S O E C}$ & $\lambda_{S O E C} \frac{0.5 \cdot \sigma_{\text {bio }}}{\eta_{\text {SOEC }}}$ \\
\hline Biorefinery & SOEC power demand & & \\
\hline & & & \\
\hline \\
NATURAL GAS FLOWS
\end{tabular}




\begin{tabular}{|c|c|c|c|}
\hline Horsens CHP & Gas turbine natural gas consumption & $\dot{e}_{n g, g t}$ & $\sigma_{g t} \cdot \lambda_{g t}$ \\
\hline Butchery & Gas boiler natural gas consumption & $\dot{e}_{n g, g b}$ & $\sigma_{\text {ind }} \lambda_{g b}\left(0.35+\beta_{n g}\right)$ \\
\hline \multicolumn{4}{|c|}{ PRODUCT GAS and OFF-PRODUCT GAS FLOWS } \\
\hline \multirow[t]{3}{*}{ Biorefinery } & Gasifier, product gas generation & $\dot{e}_{\text {syngas }}$ & $0.9294 \cdot \sigma_{\text {bio }}$ \\
\hline & Methanol off-product gas, air blown & $\dot{e}_{\text {synoff,air }}$ & $0.24 \cdot \sigma_{\text {bio }} \lambda_{\text {meth }}$ \\
\hline & Methanol off-product gas, oxygen blown & $\dot{e}_{\text {synoff }, O_{2}}$ & $0.02 \cdot \sigma_{\text {bio }} \lambda_{\text {meth }}$ \\
\hline Butchery & Gas boiler off-product gas consumption & $\dot{e}_{\text {synoff }, g b}$ & $\sigma_{i n d} \lambda_{g b}\left(1-\beta_{n g}\right)$ \\
\hline \multicolumn{4}{|c|}{ HYDROGEN FLOWS } \\
\hline \multirow[t]{3}{*}{ Biorefinery } & Hydrogen, SOEC & $\dot{e}_{\mathrm{H}_{2}, \mathrm{SOEC}}$ & $0.5 \cdot \lambda_{S O E C} \sigma_{\text {bio }}$ \\
\hline & Hydrogen addition, oxygen-blown & $\dot{e}_{\mathrm{H}_{2}, \mathrm{O}_{2}}$ & $0.184 \cdot \lambda_{\mathrm{MeOH}, \mathrm{O}_{2}} \sigma_{\text {bio }}$ \\
\hline & Hydrogen addition, hydrogen-boost & $\dot{e}_{\mathrm{MeOH}, \mathrm{H}_{2}}+$ & $0.316 \cdot \lambda_{{\mathrm{MeOH}, \mathrm{H}_{2}}+} \sigma_{\text {bio }}$ \\
\hline \multicolumn{4}{|c|}{ METHANOL FLOWS } \\
\hline \multirow[t]{3}{*}{ Biorefinery } & Methanol, air-blown & $\dot{e}_{M e O H, a i r}$ & $0.56 \cdot \lambda_{\mathrm{MeOH}, \text { air }} \sigma_{\text {bio }}$ \\
\hline & Additional methanol, oxygen-blown & $\dot{e}_{\mathrm{MeOH}, \mathrm{O}_{2}}$ & $0.34 \cdot \lambda_{\mathrm{MeOH}, \mathrm{O}_{2}} \sigma_{\text {bio }}$ \\
\hline & Additional methanol, hydrogen-boost & $\dot{e}_{\mathrm{MeOH}, \mathrm{H}_{2}+}$ & $0.32 \cdot \lambda_{{\mathrm{MeOH}, \mathrm{H}_{2}}} \sigma_{\text {bio }}$ \\
\hline
\end{tabular}

\begin{tabular}{|c|c|c|c|}
\hline Process & Flow-description & Notation & Function [MW] \\
\hline \multicolumn{4}{|c|}{ WASTE FLOWS } \\
\hline Horsens CHP & Waste incineration boilers waste processing & $\dot{m}_{\text {waste,ran }}$ & $\sigma_{\text {ran }} \cdot \lambda_{\text {ran }}$ \\
\hline \multicolumn{4}{|c|}{ OXYGEN FLOWS } \\
\hline \multirow[t]{2}{*}{ Biorefinery } & SOEC, oxygen production & $\dot{m}_{\mathrm{O}_{2}, \mathrm{SOEC}}$ & $0.0337 \cdot \sigma_{b i o} \lambda_{S O E C}$ \\
\hline & Gasifier, oxygen-blown & $\dot{m}_{\mathrm{O}_{2}, \text { gasifier }}$ & $0.0124 \cdot \sigma_{\text {bio }} \lambda_{O_{2}-\text { blown }}$ \\
\hline
\end{tabular}




\section{Appendix B - CHOP-reduction of external operating condition data}

This appendix describes the applied data aggregation procedure using the CHOP method [30].

817 Through an iterative assessment, it was decided to define six important parameter intervals for the power price, five important parameter intervals for the district heating demand, and four important parameter intervals for the industry utility demand. The applied interval break points are presented in Table 15.

820

821

The break points for relative district heating demand and relative thermal utility demand in the industry were defined based on the duration curves. The power price break points were identified iteratively by optimizing the operation of the developed model for various price schemes. Using the present-valueaveraged methanol price and natural gas price, it was found that Rankine power generation was shifted from minimum to maximum when the power price exceeded approximately 75.00 Euro/MWh. Similarly, the gas turbine power generation was maximized when power prices were around $92.00 \mathrm{Euro} / \mathrm{MWh}$ or higher, while SOEC loads were reduced to operation in oxygen-blown mode when power prices were above 90.00 Euro/MWh. For power prices above 146.00 Euro/MWh, the SOEC was found to shut down, but such high power prices were only present in 6 hours over the entire 20-year period reference dataset, hence it was not deemed relevant to add a break point at this value.

Table 15: Interval break points used in the CHOP reduction of volatile external operating conditions parameters in the case study.

\begin{tabular}{|l|l|l|l|}
\hline $\begin{array}{l}\text { Interval } \\
\text { number }\end{array}$ & $\begin{array}{l}\text { Power price, break } \\
\text { point [Euro/MWh] }\end{array}$ & $\begin{array}{l}\text { Relative District heating } \\
\text { demand, break point [-] }\end{array}$ & $\begin{array}{l}\text { Industry relative thermal utility } \\
\text { demand, break point [-] }\end{array}$ \\
\hline $\mathbf{1}$ & 20.00 & 0.25 & 0.20 \\
\hline $\mathbf{2}$ & 40.00 & 0.40 & 0.50 \\
\hline $\mathbf{3}$ & 60.00 & 0.60 & 0.80 \\
\hline $\mathbf{4}$ & 75.00 & 0.80 & 1.00 \\
\hline $\mathbf{5}$ & 90.00 & 1.00 & \\
\hline $\mathbf{6}$ & 152.53 & & \\
\hline
\end{tabular}

Using the interval break points in Table 15, the resulting CHOP reduced dataset of the reference scenario is presented in Table 16. The CHOP reduced dataset for the reference scenario when an interest rate of $20 \%$ was applied is presented in Table 17: CHOP dataset of the reference scenario when an interest rate of $20 \%$ was used for calculating the present value factors $\boldsymbol{t}_{\boldsymbol{p} v}$. Table 17, while the CHOP reduced dataset of the NonFlex scenario is presented in Table 18.

Table 16: CHOP dataset of the reference scenario used in the study. Notice that CHOP groups with durations of 0 are so-called 'empty' CHOP groups, meaning that no reference operating point falls within the group boundaries. Empty CHOP-groups are discarded from the final CHOP dataset and are grey-shaded in the table.

\begin{tabular}{|c|c|c|c|c|c|c|c|c|c|}
\hline $\begin{array}{l}\text { Group } \\
(p, d, i)\end{array}$ & $\boldsymbol{t}[\boldsymbol{h}]$ & $t_{P V}$ & $\begin{array}{c}\boldsymbol{c}_{\boldsymbol{p}} \\
{[€ / \boldsymbol{M W h}]}\end{array}$ & $\begin{array}{l}\alpha_{p} \\
{[T / M W h]}\end{array}$ & $\lambda_{D H}$ & $\lambda_{\text {ind }}$ & $\begin{array}{c}c_{\mathrm{MeOH}} \\
{[€ / G J]}\end{array}$ & $\begin{array}{l}c_{N G} \\
{[€ / G J]}\end{array}$ & $\begin{array}{l}c_{\text {wood }} \\
{[€ / G J]}\end{array}$ \\
\hline$(1,1,1)$ & 1524 & 1262 & 16.24 & 263 & 0.19 & 0.13 & 21.42 & 9.68 & 6.54 \\
\hline$(1,1,2)$ & 1680 & 1215 & 16.14 & 243 & 0.18 & 0.36 & 22.48 & 9.81 & 6.69 \\
\hline$(1,1,3)$ & 222 & 130 & 14.27 & 198 & 0.19 & 0.58 & 24.47 & 10.05 & 6.97 \\
\hline$(1,1,4)$ & 0 & 0 & 0.00 & 0 & 0.00 & 0.00 & 0.00 & 0.00 & 0.00 \\
\hline$(1,2,1)$ & 356 & 293 & 14.63 & 260 & 0.31 & 0.12 & 21.47 & 9.68 & 6.54 \\
\hline$(1,2,2)$ & 556 & 358 & 13.50 & 217 & 0.30 & 0.36 & 23.52 & 9.93 & 6.84 \\
\hline
\end{tabular}




\begin{tabular}{|c|c|c|c|c|c|c|c|c|c|}
\hline$(1,2,3)$ & 202 & 119 & 11.76 & 193 & 0.32 & 0.58 & 24.42 & 10.03 & 6.96 \\
\hline$(1,2,4)$ & 6 & 5 & 15.30 & 270 & 0.32 & 0.86 & 21.25 & 9.66 & 6.52 \\
\hline$(1,3,1)$ & 848 & 617 & 13.40 & 243 & 0.49 & 0.15 & 22.42 & 9.80 & 6.68 \\
\hline$(1,3,2)$ & 1494 & 912 & 12.45 & 208 & 0.51 & 0.38 & 24.04 & 9.99 & 6.91 \\
\hline$(1,3,3)$ & 636 & 332 & 9.72 & 170 & 0.51 & 0.61 & 25.74 & 10.20 & 7.15 \\
\hline$(1,3,4)$ & 42 & 23 & 11.23 & 182 & 0.51 & 0.83 & 25.21 & 10.13 & 7.08 \\
\hline$(1,4,1)$ & 494 & 381 & 14.65 & 253 & 0.67 & 0.16 & 21.96 & 9.74 & 6.62 \\
\hline$(1,4,2)$ & 992 & 792 & 16.14 & 260 & 0.71 & 0.36 & 21.68 & 9.71 & 6.58 \\
\hline$(1,4,3)$ & 270 & 206 & 17.36 & 252 & 0.72 & 0.57 & 22.04 & 9.76 & 6.63 \\
\hline$(1,4,4)$ & 0 & 0 & 0.00 & 0 & 0.00 & 0.00 & 0.00 & 0.00 & 0.00 \\
\hline$(1,5,1)$ & 138 & 117 & 17.15 & 270 & 0.89 & 0.17 & 21.25 & 9.66 & 6.52 \\
\hline$(1,5,2)$ & 270 & 228 & 16.72 & 270 & 0.87 & 0.31 & 21.25 & 9.66 & 6.52 \\
\hline$(1,5,3)$ & 42 & 36 & 18.51 & 270 & 0.86 & 0.56 & 21.25 & 9.66 & 6.52 \\
\hline$(1,5,4)$ & 0 & 0 & 0.00 & 0 & 0.00 & 0.00 & 0.00 & 0.00 & 0.00 \\
\hline$(2,1,1)$ & 7572 & 5513 & 29.44 & 210 & 0.19 & 0.12 & 22.59 & 9.77 & 6.67 \\
\hline$(2,1,2)$ & 11940 & 9098 & 28.41 & 244 & 0.19 & 0.36 & 22.09 & 9.75 & 6.63 \\
\hline$(2,1,3)$ & 2438 & 1874 & 30.65 & 249 & 0.21 & 0.58 & 22.00 & 9.74 & 6.62 \\
\hline$(2,1,4)$ & 24 & 20 & 30.51 & 270 & 0.19 & 0.82 & 21.25 & 9.66 & 6.52 \\
\hline$(2,2,1)$ & 2028 & 1442 & 29.67 & 210 & 0.32 & 0.13 & 22.77 & 9.80 & 6.70 \\
\hline$(2,2,2)$ & 2984 & 2290 & 28.64 & 247 & 0.32 & 0.37 & 22.02 & 9.74 & 6.62 \\
\hline$(2,2,3)$ & 992 & 753 & 30.90 & 247 & 0.31 & 0.58 & 22.10 & 9.76 & 6.64 \\
\hline$(2,2,4)$ & 6 & 3 & 33.30 & 112 & 0.25 & 0.86 & 28.34 & 10.51 & 7.52 \\
\hline$(2,3,1)$ & 3500 & 2606 & 29.17 & 223 & 0.49 & 0.15 & 22.36 & 9.76 & 6.65 \\
\hline$(2,3,2)$ & 6994 & 5419 & 29.16 & 246 & 0.49 & 0.37 & 21.96 & 9.73 & 6.61 \\
\hline$(2,3,3)$ & 2958 & 2273 & 32.31 & 248 & 0.51 & 0.61 & 22.01 & 9.74 & 6.62 \\
\hline$(2,3,4)$ & 48 & 38 & 29.84 & 259 & 0.53 & 0.83 & 21.73 & 9.72 & 6.59 \\
\hline$(2,4,1)$ & 3638 & 2756 & 30.29 & 231 & 0.70 & 0.17 & 22.19 & 9.74 & 6.63 \\
\hline$(2,4,2)$ & 6526 & 5111 & 29.41 & 247 & 0.70 & 0.37 & 21.88 & 9.72 & 6.60 \\
\hline$(2,4,3)$ & 4162 & 3337 & 30.09 & 258 & 0.70 & 0.61 & 21.67 & 9.70 & 6.57 \\
\hline$(2,4,4)$ & 216 & 173 & 31.83 & 261 & 0.72 & 0.85 & 21.67 & 9.71 & 6.58 \\
\hline$(2,5,1)$ & 768 & 615 & 30.01 & 248 & 0.86 & 0.17 & 21.73 & 9.70 & 6.57 \\
\hline$(2,5,2)$ & 2052 & 1689 & 29.00 & 259 & 0.87 & 0.37 & 21.48 & 9.68 & 6.55 \\
\hline$(2,5,3)$ & 1460 & 1233 & 29.23 & 269 & 0.86 & 0.61 & 21.26 & 9.66 & 6.52 \\
\hline$(2,5,4)$ & 90 & 76 & 31.93 & 270 & 0.82 & 0.84 & 21.25 & 9.66 & 6.52 \\
\hline$(3,1,1)$ & 6834 & 3653 & 49.07 & 113 & 0.18 & 0.13 & 25.78 & 10.11 & 7.09 \\
\hline$(3,1,2)$ & 13388 & 7306 & 49.63 & 116 & 0.17 & 0.36 & 25.55 & 10.08 & 7.06 \\
\hline$(3,1,3)$ & 2304 & 1275 & 49.59 & 131 & 0.20 & 0.58 & 25.35 & 10.07 & 7.04 \\
\hline$(3,1,4)$ & 30 & 20 & 50.80 & 153 & 0.18 & 0.82 & 23.75 & 9.86 & 6.80 \\
\hline$(3,2,1)$ & 2100 & 1098 & 50.79 & 113 & 0.34 & 0.14 & 26.01 & 10.15 & 7.13 \\
\hline$(3,2,2)$ & 4458 & 2361 & 51.59 & 115 & 0.34 & 0.37 & 25.86 & 10.13 & 7.11 \\
\hline$(3,2,3)$ & 762 & 382 & 49.94 & 131 & 0.33 & 0.58 & 26.37 & 10.23 & 7.21 \\
\hline$(3,2,4)$ & 0 & 0 & 0.00 & 0 & 0.00 & 0.00 & 0.00 & 0.00 & 0.00 \\
\hline$(3,3,1)$ & 2492 & 1375 & 50.74 & 114 & 0.49 & 0.15 & 25.45 & 10.06 & 7.04 \\
\hline
\end{tabular}




\begin{tabular}{|c|c|c|c|c|c|c|c|c|c|}
\hline$(3,3,2)$ & 5848 & 3139 & 51.33 & 113 & 0.50 & 0.38 & 25.74 & 10.10 & 7.09 \\
\hline$(3,3,3)$ & 2272 & 1154 & 50.41 & 118 & 0.52 & 0.59 & 26.29 & 10.20 & 7.18 \\
\hline$(3,3,4)$ & 80 & 43 & 46.97 & 168 & 0.51 & 0.84 & 25.42 & 10.14 & 7.10 \\
\hline$(3,4,1)$ & 1956 & 1098 & 48.42 & 117 & 0.69 & 0.17 & 25.27 & 10.04 & 7.01 \\
\hline$(3,4,2)$ & 4692 & 2657 & 49.74 & 120 & 0.69 & 0.35 & 25.17 & 10.03 & 7.00 \\
\hline$(3,4,3)$ & 2892 & 1663 & 50.07 & 124 & 0.69 & 0.60 & 25.01 & 10.01 & 6.98 \\
\hline$(3,4,4)$ & 126 & 77 & 46.52 & 174 & 0.71 & 0.86 & 24.16 & 9.96 & 6.89 \\
\hline$(3,5,1)$ & 192 & 116 & 49.07 & 112 & 0.86 & 0.17 & 24.63 & 9.93 & 6.90 \\
\hline$(3,5,2)$ & 634 & 410 & 47.10 & 149 & 0.85 & 0.37 & 23.83 & 9.87 & 6.81 \\
\hline$(3,5,3)$ & 366 & 245 & 46.95 & 168 & 0.86 & 0.62 & 23.44 & 9.84 & 6.77 \\
\hline$(3,5,4)$ & 0 & 0 & 0.00 & 0 & 0.00 & 0.00 & 0.00 & 0.00 & 0.00 \\
\hline$(4,1,1)$ & 2492 & 1146 & 65.06 & 112 & 0.17 & 0.13 & 27.43 & 10.37 & 7.37 \\
\hline$(4,1,2)$ & 7348 & 3821 & 65.38 & 112 & 0.18 & 0.37 & 26.07 & 10.15 & 7.14 \\
\hline$(4,1,3)$ & 2000 & 1071 & 66.46 & 112 & 0.19 & 0.58 & 25.77 & 10.11 & 7.09 \\
\hline$(4,1,4)$ & 32 & 15 & 64.99 & 112 & 0.17 & 0.82 & 27.15 & 10.32 & 7.32 \\
\hline$(4,2,1)$ & 1030 & 468 & 65.13 & 112 & 0.34 & 0.15 & 27.58 & 10.39 & 7.39 \\
\hline$(4,2,2)$ & 2844 & 1384 & 65.21 & 112 & 0.34 & 0.37 & 26.79 & 10.27 & 7.26 \\
\hline$(4,2,3)$ & 890 & 466 & 65.29 & 112 & 0.33 & 0.59 & 26.00 & 10.14 & 7.13 \\
\hline$(4,2,4)$ & 0 & 0 & 0.00 & 0 & 0.00 & 0.00 & 0.00 & 0.00 & 0.00 \\
\hline$(4,3,1)$ & 2202 & 1084 & 65.10 & 112 & 0.50 & 0.16 & 26.66 & 10.25 & 7.24 \\
\hline$(4,3,2)$ & 5302 & 2782 & 66.48 & 112 & 0.49 & 0.37 & 25.97 & 10.14 & 7.12 \\
\hline$(4,3,3)$ & 3496 & 1846 & 67.49 & 112 & 0.50 & 0.61 & 25.91 & 10.13 & 7.11 \\
\hline$(4,3,4)$ & 188 & 94 & 68.17 & 112 & 0.51 & 0.83 & 26.44 & 10.21 & 7.20 \\
\hline$(4,4,1)$ & 1318 & 730 & 67.74 & 112 & 0.68 & 0.17 & 25.42 & 10.05 & 7.03 \\
\hline$(4,4,2)$ & 3520 & 1979 & 67.66 & 112 & 0.69 & 0.36 & 25.28 & 10.03 & 7.01 \\
\hline$(4,4,3)$ & 3192 & 1768 & 68.52 & 112 & 0.68 & 0.63 & 25.43 & 10.05 & 7.03 \\
\hline$(4,4,4)$ & 208 & 117 & 68.98 & 112 & 0.69 & 0.85 & 25.28 & 10.03 & 7.01 \\
\hline$(4,5,1)$ & 192 & 116 & 64.98 & 112 & 0.85 & 0.16 & 24.63 & 9.93 & 6.90 \\
\hline$(4,5,2)$ & 576 & 347 & 66.38 & 112 & 0.86 & 0.34 & 24.63 & 9.93 & 6.90 \\
\hline$(4,5,3)$ & 160 & 96 & 65.58 & 112 & 0.89 & 0.60 & 24.63 & 9.93 & 6.90 \\
\hline$(4,5,4)$ & 0 & 0 & 0.00 & 0 & 0.00 & 0.00 & 0.00 & 0.00 & 0.00 \\
\hline$(5,1,1)$ & 1194 & 519 & 81.66 & 112 & 0.16 & 0.13 & 28.13 & 10.48 & 7.49 \\
\hline$(5,1,2)$ & 2538 & 1287 & 80.69 & 112 & 0.19 & 0.37 & 26.34 & 10.20 & 7.19 \\
\hline$(5,1,3)$ & 1172 & 616 & 80.61 & 112 & 0.20 & 0.59 & 25.96 & 10.14 & 7.12 \\
\hline$(5,1,4)$ & 0 & 0 & 0.00 & 0 & 0.00 & 0.00 & 0.00 & 0.00 & 0.00 \\
\hline$(5,2,1)$ & 360 & 154 & 80.82 & 112 & 0.34 & 0.14 & 28.34 & 10.51 & 7.52 \\
\hline$(5,2,2)$ & 952 & 452 & 80.20 & 112 & 0.35 & 0.37 & 27.07 & 10.31 & 7.31 \\
\hline$(5,2,3)$ & 640 & 314 & 80.84 & 112 & 0.34 & 0.62 & 26.69 & 10.25 & 7.24 \\
\hline$(5,2,4)$ & 12 & 5 & 78.33 & 112 & 0.37 & 0.82 & 28.34 & 10.51 & 7.52 \\
\hline$(5,3,1)$ & 572 & 246 & 82.40 & 112 & 0.51 & 0.16 & 28.27 & 10.50 & 7.51 \\
\hline$(5,3,2)$ & 1526 & 776 & 80.04 & 112 & 0.49 & 0.37 & 26.31 & 10.19 & 7.18 \\
\hline$(5,3,3)$ & 1394 & 736 & 79.44 & 112 & 0.48 & 0.63 & 25.91 & 10.13 & 7.11 \\
\hline$(5,3,4)$ & 72 & 35 & 81.81 & 112 & 0.52 & 0.84 & 26.81 & 10.27 & 7.26 \\
\hline
\end{tabular}




\begin{tabular}{|r|r|r|r|r|r|r|r|r|r|}
\hline $\mathbf{( 5 , 4 , 1 )}$ & 296 & 157 & 79.74 & 112 & 0.68 & 0.18 & 25.84 & 10.12 & 7.10 \\
\hline $\mathbf{( 5 , 4 , 2 )}$ & 1504 & 835 & 78.80 & 112 & 0.69 & 0.39 & 25.40 & 10.05 & 7.03 \\
\hline $\mathbf{( 5 , 4 , 3 )}$ & 1842 & 1044 & 78.91 & 112 & 0.70 & 0.63 & 25.20 & 10.02 & 7.00 \\
\hline $\mathbf{( 5 , 4 , 4 )}$ & 206 & 123 & 78.23 & 112 & 0.70 & 0.85 & 24.71 & 9.94 & 6.91 \\
\hline $\mathbf{( 5 , 5 , 1 )}$ & 0 & 0 & 0.00 & 0 & 0.00 & 0.00 & 0.00 & 0.00 & 0.00 \\
\hline $\mathbf{( 5 , 5 , 2 )}$ & 104 & 63 & 75.71 & 112 & 0.85 & 0.36 & 24.63 & 9.93 & 6.90 \\
\hline $\mathbf{( 5 , 5 , 3 )}$ & 0 & 0 & 0.00 & 0 & 0.00 & 0.00 & 0.00 & 0.00 & 0.00 \\
\hline $\mathbf{( 5 , 5 , 4 )}$ & 0 & 0 & 0.00 & 0 & 0.00 & 0.00 & 0.00 & 0.00 & 0.00 \\
\hline $\mathbf{( 6 , 1 , 1 )}$ & 234 & 100 & 120.30 & 112 & 0.16 & 0.12 & 28.34 & 10.51 & 7.52 \\
\hline $\mathbf{( 6 , 1 , 2 )}$ & 396 & 186 & 117.19 & 112 & 0.17 & 0.38 & 27.19 & 10.33 & 7.33 \\
\hline $\mathbf{( 6 , 1 , 3 )}$ & 92 & 45 & 125.05 & 112 & 0.19 & 0.61 & 26.75 & 10.26 & 7.25 \\
\hline $\mathbf{( 6 , 1 , 4 )}$ & 14 & 7 & 113.04 & 112 & 0.20 & 0.83 & 25.92 & 10.13 & 7.12 \\
\hline $\mathbf{( 6 , 2 , 1 )}$ & 90 & 38 & 133.66 & 112 & 0.33 & 0.14 & 28.34 & 10.51 & 7.52 \\
\hline $\mathbf{( 6 , 2 , 2 )}$ & 188 & 82 & 114.44 & 112 & 0.35 & 0.33 & 28.12 & 10.48 & 7.48 \\
\hline $\mathbf{( 6 , 2 , 3 )}$ & 100 & 46 & 121.10 & 112 & 0.36 & 0.61 & 27.55 & 10.39 & 7.39 \\
\hline $\mathbf{( 6 , 2 , 4 )}$ & 8 & 5 & 139.60 & 112 & 0.30 & 0.86 & 24.63 & 9.93 & 6.90 \\
\hline $\mathbf{( 6 , 3 , 1 )}$ & 66 & 28 & 116.32 & 112 & 0.49 & 0.16 & 28.34 & 10.51 & 7.52 \\
\hline $\mathbf{( 6 , 3 , 2})$ & 242 & 126 & 115.62 & 112 & 0.50 & 0.39 & 26.07 & 10.15 & 7.14 \\
\hline $\mathbf{( 6 , 3 , 3 )}$ & 110 & 57 & 105.12 & 112 & 0.48 & 0.65 & 26.14 & 10.17 & 7.15 \\
\hline $\mathbf{( 6 , 3 , 4 )}$ & 6 & 3 & 134.45 & 112 & 0.46 & 0.89 & 28.34 & 10.51 & 7.52 \\
\hline $\mathbf{( 6 , 4 , 1 )}$ & 74 & 37 & 116.66 & 112 & 0.66 & 0.16 & 26.42 & 10.21 & 7.20 \\
\hline $\mathbf{( 6 , 4 , 2 )}$ & 472 & 234 & 111.87 & 112 & 0.67 & 0.40 & 26.58 & 10.24 & 7.23 \\
\hline $\mathbf{( 6 , 4 , 3 )}$ & 134 & 63 & 101.75 & 112 & 0.67 & 0.60 & 27.20 & 10.33 & 7.33 \\
\hline $\mathbf{( 6 , 4 , 4 )}$ & 6 & 3 & 99.18 & 112 & 0.61 & 0.81 & 28.34 & 10.51 & 7.52 \\
\hline $\mathbf{( 6 , 5 , 1 )}$ & 0 & 0 & 0.00 & 0 & 0.00 & 0.00 & 0.00 & 0.00 & 0.00 \\
\hline $\mathbf{( 6 , 5 , 2 )}$ & 0 & 0 & 0.00 & 0 & 0.00 & 0.00 & 0.00 & 0.00 & 0.00 \\
\hline $\mathbf{( 6 , 5 , 3 )}$ & 0 & 0 & 0.00 & 0 & 0.00 & 0.00 & 0.00 & 0.00 & 0.00 \\
\hline $\mathbf{( 6 , 5 , 4 )}$ & 0 & 0 & 0.00 & 0 & 0.00 & 0.00 & 0.00 & 0.00 & 0.00 \\
\hline
\end{tabular}

Table 17: CHOP dataset of the reference scenario when an interest rate of $20 \%$ was used for calculating the present value factors $t_{p v}$.

\begin{tabular}{|c|c|c|c|c|c|c|c|c|c|}
\hline $\begin{array}{l}\text { Group } \\
(p, d, i)\end{array}$ & $t[h]$ & $t_{P V}$ & $\begin{array}{c}\boldsymbol{c}_{\boldsymbol{p}} \\
{[€ / \boldsymbol{M W h}]}\end{array}$ & $\begin{array}{l}\alpha_{p} \\
{[T / M W h]}\end{array}$ & $\lambda_{D H}$ & $\lambda_{\text {ind }}$ & $\begin{array}{c}c_{\mathrm{MeOH}} \\
{[€ / G J]}\end{array}$ & $\begin{array}{l}c_{N G} \\
{[€ / G J]}\end{array}$ & $\begin{array}{l}c_{\text {wood }} \\
{[€ / G J]}\end{array}$ \\
\hline$(1,1,1)$ & 1524 & 804 & 16.24 & 263 & 0.19 & 0.13 & 21.42 & 9.68 & 6.54 \\
\hline$(1,1,2)$ & 1680 & 680 & 16.14 & 243 & 0.18 & 0.36 & 22.48 & 9.81 & 6.69 \\
\hline$(1,1,3)$ & 222 & 53 & 14.27 & 198 & 0.19 & 0.58 & 24.47 & 10.05 & 6.97 \\
\hline$(1,1,4)$ & 0 & 0 & 0.00 & 0 & 0.00 & 0.00 & 0.00 & 0.00 & 0.00 \\
\hline$(1,2,1)$ & 356 & 185 & 14.63 & 260 & 0.31 & 0.12 & 21.47 & 9.68 & 6.54 \\
\hline$(1,2,2)$ & 556 & 170 & 13.50 & 217 & 0.30 & 0.36 & 23.52 & 9.93 & 6.84 \\
\hline$(1,2,3)$ & 202 & 47 & 11.76 & 193 & 0.32 & 0.58 & 24.42 & 10.03 & 6.96 \\
\hline$(1,2,4)$ & 6 & 3 & 15.30 & 270 & 0.32 & 0.86 & 21.25 & 9.66 & 6.52 \\
\hline$(1,3,1)$ & 848 & 347 & 13.40 & 243 & 0.49 & 0.15 & 22.42 & 9.80 & 6.68 \\
\hline$(1,3,2)$ & 1494 & 399 & 12.45 & 208 & 0.51 & 0.38 & 24.04 & 9.99 & 6.91 \\
\hline
\end{tabular}




\begin{tabular}{|c|c|c|c|c|c|c|c|c|c|}
\hline$(1,3,3)$ & 636 & 101 & 9.72 & 170 & 0.51 & 0.61 & 25.74 & 10.20 & 7.15 \\
\hline$(1,3,4)$ & 42 & 8 & 11.23 & 182 & 0.51 & 0.83 & 25.21 & 10.13 & 7.08 \\
\hline$(1,4,1)$ & 494 & 228 & 14.65 & 253 & 0.67 & 0.16 & 21.96 & 9.74 & 6.62 \\
\hline$(1,4,2)$ & 992 & 491 & 16.14 & 260 & 0.71 & 0.36 & 21.68 & 9.71 & 6.58 \\
\hline$(1,4,3)$ & 270 & 122 & 17.36 & 252 & 0.72 & 0.57 & 22.04 & 9.76 & 6.63 \\
\hline$(1,4,4)$ & 0 & 0 & 0.00 & 0 & 0.00 & 0.00 & 0.00 & 0.00 & 0.00 \\
\hline$(1,5,1)$ & 138 & 76 & 17.15 & 270 & 0.89 & 0.17 & 21.25 & 9.66 & 6.52 \\
\hline$(1,5,2)$ & 270 & 150 & 16.72 & 270 & 0.87 & 0.31 & 21.25 & 9.66 & 6.52 \\
\hline$(1,5,3)$ & 42 & 23 & 18.51 & 270 & 0.86 & 0.56 & 21.25 & 9.66 & 6.52 \\
\hline$(1,5,4)$ & 0 & 0 & 0.00 & 0 & 0.00 & 0.00 & 0.00 & 0.00 & 0.00 \\
\hline$(2,1,1)$ & 7572 & 2789 & 29.44 & 210 & 0.19 & 0.12 & 22.59 & 9.77 & 6.67 \\
\hline$(2,1,2)$ & 11940 & 5257 & 28.41 & 244 & 0.19 & 0.36 & 22.09 & 9.75 & 6.63 \\
\hline$(2,1,3)$ & 2438 & 1104 & 30.65 & 249 & 0.21 & 0.58 & 22.00 & 9.74 & 6.62 \\
\hline$(2,1,4)$ & 24 & 13 & 30.51 & 270 & 0.19 & 0.82 & 21.25 & 9.66 & 6.52 \\
\hline$(2,2,1)$ & 2028 & 718 & 29.67 & 210 & 0.32 & 0.13 & 22.77 & 9.80 & 6.70 \\
\hline$(2,2,2)$ & 2984 & 1341 & 28.64 & 247 & 0.32 & 0.37 & 22.02 & 9.74 & 6.62 \\
\hline$(2,2,3)$ & 992 & 439 & 30.90 & 247 & 0.31 & 0.58 & 22.10 & 9.76 & 6.64 \\
\hline$(2,2,4)$ & 6 & 0 & 33.30 & 112 & 0.25 & 0.86 & 28.34 & 10.51 & 7.52 \\
\hline$(2,3,1)$ & 3500 & 1394 & 29.17 & 223 & 0.49 & 0.15 & 22.36 & 9.76 & 6.65 \\
\hline$(2,3,2)$ & 6994 & 3184 & 29.16 & 246 & 0.49 & 0.37 & 21.96 & 9.73 & 6.61 \\
\hline$(2,3,3)$ & 2958 & 1336 & 32.31 & 248 & 0.51 & 0.61 & 22.01 & 9.74 & 6.62 \\
\hline$(2,3,4)$ & 48 & 24 & 29.84 & 259 & 0.53 & 0.83 & 21.73 & 9.72 & 6.59 \\
\hline$(2,4,1)$ & 3638 & 1528 & 30.29 & 231 & 0.70 & 0.17 & 22.19 & 9.74 & 6.63 \\
\hline$(2,4,2)$ & 6526 & 3031 & 29.41 & 247 & 0.70 & 0.37 & 21.88 & 9.72 & 6.60 \\
\hline$(2,4,3)$ & 4162 & 2062 & 30.09 & 258 & 0.70 & 0.61 & 21.67 & 9.70 & 6.57 \\
\hline$(2,4,4)$ & 216 & 107 & 31.83 & 261 & 0.72 & 0.85 & 21.67 & 9.71 & 6.58 \\
\hline$(2,5,1)$ & 768 & 369 & 30.01 & 248 & 0.86 & 0.17 & 21.73 & 9.70 & 6.57 \\
\hline$(2,5,2)$ & 2052 & 1062 & 29.00 & 259 & 0.87 & 0.37 & 21.48 & 9.68 & 6.55 \\
\hline$(2,5,3)$ & 1460 & 806 & 29.23 & 269 & 0.86 & 0.61 & 21.26 & 9.66 & 6.52 \\
\hline$(2,5,4)$ & 90 & 50 & 31.93 & 270 & 0.82 & 0.84 & 21.25 & 9.66 & 6.52 \\
\hline$(3,1,1)$ & 6834 & 792 & 49.07 & 113 & 0.18 & 0.13 & 25.78 & 10.11 & 7.09 \\
\hline$(3,1,2)$ & 13388 & 1694 & 49.63 & 116 & 0.17 & 0.36 & 25.55 & 10.08 & 7.06 \\
\hline$(3,1,3)$ & 2304 & 335 & 49.59 & 131 & 0.20 & 0.58 & 25.35 & 10.07 & 7.04 \\
\hline$(3,1,4)$ & 30 & 7 & 50.80 & 153 & 0.18 & 0.82 & 23.75 & 9.86 & 6.80 \\
\hline$(3,2,1)$ & 2100 & 226 & 50.79 & 113 & 0.34 & 0.14 & 26.01 & 10.15 & 7.13 \\
\hline$(3,2,2)$ & 4458 & 510 & 51.59 & 115 & 0.34 & 0.37 & 25.86 & 10.13 & 7.11 \\
\hline$(3,2,3)$ & 762 & 83 & 49.94 & 131 & 0.33 & 0.58 & 26.37 & 10.23 & 7.21 \\
\hline$(3,2,4)$ & 0 & 0 & 0.00 & 0 & 0.00 & 0.00 & 0.00 & 0.00 & 0.00 \\
\hline$(3,3,1)$ & 2492 & 321 & 50.74 & 114 & 0.49 & 0.15 & 25.45 & 10.06 & 7.04 \\
\hline$(3,3,2)$ & 5848 & 687 & 51.33 & 113 & 0.50 & 0.38 & 25.74 & 10.10 & 7.09 \\
\hline$(3,3,3)$ & 2272 & 232 & 50.41 & 118 & 0.52 & 0.59 & 26.29 & 10.20 & 7.18 \\
\hline$(3,3,4)$ & 80 & 14 & 46.97 & 168 & 0.51 & 0.84 & 25.42 & 10.14 & 7.10 \\
\hline$(3,4,1)$ & 1956 & 269 & 48.42 & 117 & 0.69 & 0.17 & 25.27 & 10.04 & 7.01 \\
\hline
\end{tabular}




\begin{tabular}{|c|c|c|c|c|c|c|c|c|c|}
\hline$(3,4,2)$ & 4692 & 677 & 49.74 & 120 & 0.69 & 0.35 & 25.17 & 10.03 & 7.00 \\
\hline$(3,4,3)$ & 2892 & 444 & 50.07 & 124 & 0.69 & 0.60 & 25.01 & 10.01 & 6.98 \\
\hline$(3,4,4)$ & 126 & 29 & 46.52 & 174 & 0.71 & 0.86 & 24.16 & 9.96 & 6.89 \\
\hline$(3,5,1)$ & 192 & 31 & 49.07 & 112 & 0.86 & 0.17 & 24.63 & 9.93 & 6.90 \\
\hline$(3,5,2)$ & 634 & 147 & 47.10 & 149 & 0.85 & 0.37 & 23.83 & 9.87 & 6.81 \\
\hline$(3,5,3)$ & 366 & 99 & 46.95 & 168 & 0.86 & 0.62 & 23.44 & 9.84 & 6.77 \\
\hline$(3,5,4)$ & 0 & 0 & 0.00 & 0 & 0.00 & 0.00 & 0.00 & 0.00 & 0.00 \\
\hline$(4,1,1)$ & 2492 & 162 & 65.06 & 112 & 0.17 & 0.13 & 27.43 & 10.37 & 7.37 \\
\hline$(4,1,2)$ & 7348 & 773 & 65.38 & 112 & 0.18 & 0.37 & 26.07 & 10.15 & 7.14 \\
\hline$(4,1,3)$ & 2000 & 231 & 66.46 & 112 & 0.19 & 0.58 & 25.77 & 10.11 & 7.09 \\
\hline$(4,1,4)$ & 32 & 2 & 64.99 & 112 & 0.17 & 0.82 & 27.15 & 10.32 & 7.32 \\
\hline$(4,2,1)$ & 1030 & 63 & 65.13 & 112 & 0.34 & 0.15 & 27.58 & 10.39 & 7.39 \\
\hline$(4,2,2)$ & 2844 & 236 & 65.21 & 112 & 0.34 & 0.37 & 26.79 & 10.27 & 7.26 \\
\hline$(4,2,3)$ & 890 & 96 & 65.29 & 112 & 0.33 & 0.59 & 26.00 & 10.14 & 7.13 \\
\hline$(4,2,4)$ & 0 & 0 & 0.00 & 0 & 0.00 & 0.00 & 0.00 & 0.00 & 0.00 \\
\hline$(4,3,1)$ & 2202 & 191 & 65.10 & 112 & 0.50 & 0.16 & 26.66 & 10.25 & 7.24 \\
\hline$(4,3,2)$ & 5302 & 575 & 66.48 & 112 & 0.49 & 0.37 & 25.97 & 10.14 & 7.12 \\
\hline$(4,3,3)$ & 3496 & 387 & 67.49 & 112 & 0.50 & 0.61 & 25.91 & 10.13 & 7.11 \\
\hline$(4,3,4)$ & 188 & 18 & 68.17 & 112 & 0.51 & 0.83 & 26.44 & 10.21 & 7.20 \\
\hline$(4,4,1)$ & 1318 & 169 & 67.74 & 112 & 0.68 & 0.17 & 25.42 & 10.05 & 7.03 \\
\hline$(4,4,2)$ & 3520 & 470 & 67.66 & 112 & 0.69 & 0.36 & 25.28 & 10.03 & 7.01 \\
\hline$(4,4,3)$ & 3192 & 408 & 68.52 & 112 & 0.68 & 0.63 & 25.43 & 10.05 & 7.03 \\
\hline$(4,4,4)$ & 208 & 28 & 68.98 & 112 & 0.69 & 0.85 & 25.28 & 10.03 & 7.01 \\
\hline$(4,5,1)$ & 192 & 31 & 64.98 & 112 & 0.85 & 0.16 & 24.63 & 9.93 & 6.90 \\
\hline$(4,5,2)$ & 576 & 93 & 66.38 & 112 & 0.86 & 0.34 & 24.63 & 9.93 & 6.90 \\
\hline$(4,5,3)$ & 160 & 26 & 65.58 & 112 & 0.89 & 0.60 & 24.63 & 9.93 & 6.90 \\
\hline$(4,5,4)$ & 0 & 0 & 0.00 & 0 & 0.00 & 0.00 & 0.00 & 0.00 & 0.00 \\
\hline$(5,1,1)$ & 1194 & 57 & 81.66 & 112 & 0.16 & 0.13 & 28.13 & 10.48 & 7.49 \\
\hline$(5,1,2)$ & 2538 & 245 & 80.69 & 112 & 0.19 & 0.37 & 26.34 & 10.20 & 7.19 \\
\hline$(5,1,3)$ & 1172 & 128 & 80.61 & 112 & 0.20 & 0.59 & 25.96 & 10.14 & 7.12 \\
\hline$(5,1,4)$ & 0 & 0 & 0.00 & 0 & 0.00 & 0.00 & 0.00 & 0.00 & 0.00 \\
\hline$(5,2,1)$ & 360 & 16 & 80.82 & 112 & 0.34 & 0.14 & 28.34 & 10.51 & 7.52 \\
\hline$(5,2,2)$ & 952 & 71 & 80.20 & 112 & 0.35 & 0.37 & 27.07 & 10.31 & 7.31 \\
\hline$(5,2,3)$ & 640 & 55 & 80.84 & 112 & 0.34 & 0.62 & 26.69 & 10.25 & 7.24 \\
\hline$(5,2,4)$ & 12 & 1 & 78.33 & 112 & 0.37 & 0.82 & 28.34 & 10.51 & 7.52 \\
\hline$(5,3,1)$ & 572 & 26 & 82.40 & 112 & 0.51 & 0.16 & 28.27 & 10.50 & 7.51 \\
\hline$(5,3,2)$ & 1526 & 149 & 80.04 & 112 & 0.49 & 0.37 & 26.31 & 10.19 & 7.18 \\
\hline$(5,3,3)$ & 1394 & 154 & 79.44 & 112 & 0.48 & 0.63 & 25.91 & 10.13 & 7.11 \\
\hline$(5,3,4)$ & 72 & 6 & 81.81 & 112 & 0.52 & 0.84 & 26.81 & 10.27 & 7.26 \\
\hline$(5,4,1)$ & 296 & 33 & 79.74 & 112 & 0.68 & 0.18 & 25.84 & 10.12 & 7.10 \\
\hline$(5,4,2)$ & 1504 & 194 & 78.80 & 112 & 0.69 & 0.39 & 25.40 & 10.05 & 7.03 \\
\hline$(5,4,3)$ & 1842 & 251 & 78.91 & 112 & 0.70 & 0.63 & 25.20 & 10.02 & 7.00 \\
\hline$(5,4,4)$ & 206 & 32 & 78.23 & 112 & 0.70 & 0.85 & 24.71 & 9.94 & 6.91 \\
\hline
\end{tabular}




\begin{tabular}{|c|c|c|c|c|c|c|c|c|c|}
\hline$(5,5,1)$ & 0 & 0 & 0.00 & 0 & 0.00 & 0.00 & 0.00 & 0.00 & 0.00 \\
\hline$(5,5,2)$ & 104 & 17 & 75.71 & 112 & 0.85 & 0.36 & 24.63 & 9.93 & 6.90 \\
\hline$(5,5,3)$ & 0 & 0 & 0.00 & 0 & 0.00 & 0.00 & 0.00 & 0.00 & 0.00 \\
\hline$(5,5,4)$ & 0 & 0 & 0.00 & 0 & 0.00 & 0.00 & 0.00 & 0.00 & 0.00 \\
\hline$(6,1,1)$ & 234 & 10 & 120.30 & 112 & 0.16 & 0.12 & 28.34 & 10.51 & 7.52 \\
\hline$(6,1,2)$ & 396 & 28 & 117.19 & 112 & 0.17 & 0.38 & 27.19 & 10.33 & 7.33 \\
\hline$(6,1,3)$ & 92 & 8 & 125.05 & 112 & 0.19 & 0.61 & 26.75 & 10.26 & 7.25 \\
\hline$(6,1,4)$ & 14 & 2 & 113.04 & 112 & 0.20 & 0.83 & 25.92 & 10.13 & 7.12 \\
\hline$(6,2,1)$ & 90 & 4 & 133.66 & 112 & 0.33 & 0.14 & 28.34 & 10.51 & 7.52 \\
\hline$(6,2,2)$ & 188 & 9 & 114.44 & 112 & 0.35 & 0.33 & 28.12 & 10.48 & 7.48 \\
\hline$(6,2,3)$ & 100 & 6 & 121.10 & 112 & 0.36 & 0.61 & 27.55 & 10.39 & 7.39 \\
\hline$(6,2,4)$ & 8 & 1 & 139.60 & 112 & 0.30 & 0.86 & 24.63 & 9.93 & 6.90 \\
\hline$(6,3,1)$ & 66 & 3 & 116.32 & 112 & 0.49 & 0.16 & 28.34 & 10.51 & 7.52 \\
\hline$(6,3,2)$ & 242 & 25 & 115.62 & 112 & 0.50 & 0.39 & 26.07 & 10.15 & 7.14 \\
\hline$(6,3,3)$ & 110 & 11 & 105.12 & 112 & 0.48 & 0.65 & 26.14 & 10.17 & 7.15 \\
\hline$(6,3,4)$ & 6 & 0 & 134.45 & 112 & 0.46 & 0.89 & 28.34 & 10.51 & 7.52 \\
\hline$(6,4,1)$ & 74 & 7 & 116.66 & 112 & 0.66 & 0.16 & 26.42 & 10.21 & 7.20 \\
\hline$(6,4,2)$ & 472 & 42 & 111.87 & 112 & 0.67 & 0.40 & 26.58 & 10.24 & 7.23 \\
\hline$(6,4,3)$ & 134 & 10 & 101.75 & 112 & 0.67 & 0.60 & 27.20 & 10.33 & 7.33 \\
\hline$(6,4,4)$ & 6 & 0 & 99.18 & 112 & 0.61 & 0.81 & 28.34 & 10.51 & 7.52 \\
\hline$(6,5,1)$ & 0 & 0 & 0.00 & 0 & 0.00 & 0.00 & 0.00 & 0.00 & 0.00 \\
\hline$(6,5,2)$ & 0 & 0 & 0.00 & 0 & 0.00 & 0.00 & 0.00 & 0.00 & 0.00 \\
\hline$(6,5,3)$ & 0 & 0 & 0.00 & 0 & 0.00 & 0.00 & 0.00 & 0.00 & 0.00 \\
\hline$(6,5,4)$ & 0 & 0 & 0.00 & 0 & 0.00 & 0.00 & 0.00 & 0.00 & 0.00 \\
\hline
\end{tabular}

Table 18: CHOP dataset for the NonFlex scenario used in the study. Notice that $\mathrm{CHOP}$ groups with durations of 0 are so-called 'empty' CHOP groups, meaning that no reference operating point falls within the group boundaries. Empty CHOP-groups are discarded from the final CHOP dataset and are grey-shaded in the table.

\begin{tabular}{|c|c|c|c|c|c|c|c|c|c|}
\hline $\begin{array}{l}\text { Group } \\
(p, d, i)\end{array}$ & $t[h]$ & $t_{P V}$ & $\begin{array}{c}\boldsymbol{c}_{\boldsymbol{p}} \\
{[€ / \boldsymbol{M W h}]}\end{array}$ & $\begin{array}{l}\alpha_{p} \\
{[T / M W h]}\end{array}$ & $\lambda_{D H}$ & $\lambda_{\text {ind }}$ & $\begin{array}{c}c_{M e O H} \\
{[€ / G J]}\end{array}$ & $\begin{array}{l}c_{N G} \\
{[€ / G J]}\end{array}$ & $\begin{array}{l}c_{\text {wood }} \\
{[€ / G J]}\end{array}$ \\
\hline$(1,1,1)$ & 1776 & 1369.3 & 15.34 & 251 & 0.19 & 0.13 & 21.97 & 9.74 & 6.62 \\
\hline$(1,1,2)$ & 1716 & 1230.6 & 15.35 & 241 & 0.18 & 0.35 & 22.55 & 9.82 & 6.70 \\
\hline$(1,1,3)$ & 222 & 130 & 11.85 & 198 & 0.19 & 0.58 & 24.47 & 10.05 & 6.97 \\
\hline$(1,1,4)$ & 0 & 0 & 0.00 & 0 & 0.00 & 0.00 & 0.00 & 0.00 & 0.00 \\
\hline$(1,2,1)$ & 488 & 350 & 12.77 & 236 & 0.32 & 0.13 & 22.58 & 9.81 & 6.70 \\
\hline$(1,2,2)$ & 1012 & 553 & 9.65 & 180 & 0.32 & 0.36 & 25.22 & 10.13 & 7.08 \\
\hline$(1,2,3)$ & 178 & 109 & 11.90 & 200 & 0.31 & 0.57 & 24.05 & 9.98 & 6.91 \\
\hline$(1,2,4)$ & 6 & 5 & 15.30 & 270 & 0.32 & 0.86 & 21.25 & 9.66 & 6.52 \\
\hline$(1,3,1)$ & 728 & 566 & 14.27 & 255 & 0.49 & 0.14 & 21.89 & 9.74 & 6.61 \\
\hline$(1,3,2)$ & 1266 & 815 & 12.39 & 219 & 0.51 & 0.37 & 23.53 & 9.93 & 6.84 \\
\hline$(1,3,3)$ & 576 & 306 & 8.38 & 175 & 0.50 & 0.57 & 25.52 & 10.17 & 7.12 \\
\hline$(1,3,4)$ & 30 & 18 & 10.57 & 202 & 0.51 & 0.83 & 24.31 & 10.03 & 6.95 \\
\hline$(1,4,1)$ & 434 & 355 & 14.77 & 263 & 0.67 & 0.16 & 21.50 & 9.69 & 6.55 \\
\hline$(1,4,2)$ & 1070 & 825 & 15.37 & 254 & 0.71 & 0.35 & 21.95 & 9.74 & 6.62 \\
\hline
\end{tabular}




\begin{tabular}{|c|c|c|c|c|c|c|c|c|c|}
\hline$(1,4,3)$ & 240 & 193 & 16.76 & 262 & 0.73 & 0.56 & 21.63 & 9.71 & 6.57 \\
\hline$(1,4,4)$ & 0 & 0 & 0.00 & 0 & 0.00 & 0.00 & 0.00 & 0.00 & 0.00 \\
\hline$(1,5,1)$ & 138 & 117 & 17.15 & 270 & 0.89 & 0.17 & 21.25 & 9.66 & 6.52 \\
\hline$(1,5,2)$ & 270 & 228 & 16.72 & 270 & 0.87 & 0.31 & 21.25 & 9.66 & 6.52 \\
\hline$(1,5,3)$ & 42 & 36 & 18.51 & 270 & 0.86 & 0.56 & 21.25 & 9.66 & 6.52 \\
\hline$(1,5,4)$ & 0 & 0 & 0.00 & 0 & 0.00 & 0.00 & 0.00 & 0.00 & 0.00 \\
\hline$(2,1,1)$ & 7494 & 5480 & 29.34 & 211 & 0.19 & 0.12 & 22.55 & 9.77 & 6.67 \\
\hline$(2,1,2)$ & 10698 & 8568 & 28.19 & 252 & 0.19 & 0.36 & 21.70 & 9.70 & 6.57 \\
\hline$(2,1,3)$ & 2156 & 1753 & 30.52 & 258 & 0.21 & 0.58 & 21.57 & 9.69 & 6.56 \\
\hline$(2,1,4)$ & 24 & 20 & 30.51 & 270 & 0.19 & 0.82 & 21.25 & 9.66 & 6.52 \\
\hline$(2,2,1)$ & 1824 & 1355 & 29.41 & 217 & 0.32 & 0.13 & 22.41 & 9.75 & 6.65 \\
\hline$(2,2,2)$ & 2852 & 2233 & 28.25 & 250 & 0.32 & 0.37 & 21.86 & 9.72 & 6.60 \\
\hline$(2,2,3)$ & 878 & 704 & 30.72 & 257 & 0.31 & 0.58 & 21.67 & 9.70 & 6.57 \\
\hline$(2,2,4)$ & 0 & 0 & 0.00 & 0 & 0.00 & 0.00 & 0.00 & 0.00 & 0.00 \\
\hline$(2,3,1)$ & 3380 & 2555 & 29.10 & 225 & 0.49 & 0.15 & 22.24 & 9.74 & 6.63 \\
\hline$(2,3,2)$ & 6508 & 5211 & 28.98 & 251 & 0.49 & 0.37 & 21.71 & 9.70 & 6.57 \\
\hline$(2,3,3)$ & 2748 & 2183 & 32.07 & 253 & 0.51 & 0.61 & 21.75 & 9.71 & 6.58 \\
\hline$(2,3,4)$ & 54 & 41 & 29.14 & 250 & 0.54 & 0.83 & 22.14 & 9.77 & 6.65 \\
\hline$(2,4,1)$ & 3458 & 2679 & 30.16 & 234 & 0.70 & 0.17 & 22.02 & 9.72 & 6.61 \\
\hline$(2,4,2)$ & 6130 & 4942 & 29.27 & 252 & 0.70 & 0.37 & 21.66 & 9.69 & 6.57 \\
\hline$(2,4,3)$ & 3850 & 3204 & 30.13 & 264 & 0.71 & 0.61 & 21.39 & 9.67 & 6.54 \\
\hline$(2,4,4)$ & 192 & 162 & 31.84 & 270 & 0.72 & 0.85 & 21.25 & 9.66 & 6.52 \\
\hline$(2,5,1)$ & 768 & 615 & 30.01 & 248 & 0.86 & 0.17 & 21.73 & 9.70 & 6.57 \\
\hline$(2,5,2)$ & 2052 & 1689 & 29.00 & 259 & 0.87 & 0.37 & 21.48 & 9.68 & 6.55 \\
\hline$(2,5,3)$ & 1460 & 1233 & 29.23 & 269 & 0.86 & 0.61 & 21.26 & 9.66 & 6.52 \\
\hline$(2,5,4)$ & 90 & 76 & 31.93 & 270 & 0.82 & 0.84 & 21.25 & 9.66 & 6.52 \\
\hline$(3,1,1)$ & 4584 & 2692 & 47.82 & 113 & 0.18 & 0.13 & 24.86 & 9.97 & 6.94 \\
\hline$(3,1,2)$ & 9290 & 5555 & 49.07 & 118 & 0.18 & 0.36 & 24.68 & 9.95 & 6.91 \\
\hline$(3,1,3)$ & 1464 & 916 & 49.82 & 138 & 0.21 & 0.58 & 24.17 & 9.90 & 6.85 \\
\hline$(3,1,4)$ & 30 & 20 & 50.80 & 153 & 0.18 & 0.82 & 23.75 & 9.86 & 6.80 \\
\hline$(3,2,1)$ & 1320 & 765 & 49.40 & 113 & 0.34 & 0.14 & 24.99 & 9.99 & 6.96 \\
\hline$(3,2,2)$ & 3060 & 1764 & 50.63 & 116 & 0.34 & 0.36 & 25.02 & 10.00 & 6.97 \\
\hline$(3,2,3)$ & 402 & 228 & 49.29 & 144 & 0.31 & 0.56 & 25.04 & 10.05 & 7.01 \\
\hline$(3,2,4)$ & 0 & 0 & 0.00 & 0 & 0.00 & 0.00 & 0.00 & 0.00 & 0.00 \\
\hline$(3,3,1)$ & 1916 & 1129 & 50.61 & 115 & 0.48 & 0.15 & 24.82 & 9.96 & 6.94 \\
\hline$(3,3,2)$ & 4006 & 2352 & 51.66 & 113 & 0.49 & 0.38 & 24.86 & 9.97 & 6.94 \\
\hline$(3,3,3)$ & 1294 & 736 & 51.11 & 121 & 0.52 & 0.59 & 25.13 & 10.02 & 6.99 \\
\hline$(3,3,4)$ & 50 & 30 & 47.20 & 191 & 0.50 & 0.84 & 24.19 & 9.99 & 6.92 \\
\hline$(3,4,1)$ & 1464 & 888 & 47.98 & 118 & 0.69 & 0.17 & 24.55 & 9.93 & 6.89 \\
\hline$(3,4,2)$ & 3534 & 2162 & 50.01 & 122 & 0.70 & 0.35 & 24.45 & 9.92 & 6.88 \\
\hline$(3,4,3)$ & 2268 & 1396 & 50.17 & 126 & 0.70 & 0.60 & 24.38 & 9.91 & 6.87 \\
\hline$(3,4,4)$ & 84 & 59 & 45.05 & 193 & 0.73 & 0.87 & 22.90 & 9.79 & 6.71 \\
\hline$(3,5,1)$ & 192 & 116 & 49.07 & 112 & 0.86 & 0.17 & 24.63 & 9.93 & 6.90 \\
\hline
\end{tabular}




\begin{tabular}{|c|c|c|c|c|c|c|c|c|c|}
\hline$(3,5,2)$ & 634 & 410 & 47.10 & 149 & 0.85 & 0.37 & 23.83 & 9.87 & 6.81 \\
\hline$(3,5,3)$ & 366 & 245 & 46.95 & 168 & 0.86 & 0.62 & 23.44 & 9.84 & 6.77 \\
\hline$(3,5,4)$ & 0 & 0 & 0.00 & 0 & 0.00 & 0.00 & 0.00 & 0.00 & 0.00 \\
\hline$(4,1,1)$ & 1844 & 869 & 67.87 & 112 & 0.17 & 0.13 & 27.15 & 10.32 & 7.32 \\
\hline$(4,1,2)$ & 6418 & 3424 & 67.02 & 112 & 0.18 & 0.37 & 25.81 & 10.11 & 7.10 \\
\hline$(4,1,3)$ & 1610 & 904 & 66.83 & 112 & 0.19 & 0.58 & 25.29 & 10.03 & 7.01 \\
\hline$(4,1,4)$ & 14 & 7 & 69.14 & 112 & 0.21 & 0.83 & 25.92 & 10.13 & 7.12 \\
\hline$(4,2,1)$ & 664 & 312 & 67.01 & 112 & 0.33 & 0.15 & 27.19 & 10.33 & 7.33 \\
\hline$(4,2,2)$ & 2232 & 1122 & 66.63 & 112 & 0.35 & 0.37 & 26.43 & 10.21 & 7.20 \\
\hline$(4,2,3)$ & 866 & 456 & 65.98 & 112 & 0.33 & 0.59 & 25.94 & 10.14 & 7.12 \\
\hline$(4,2,4)$ & 12 & 5 & 70.69 & 112 & 0.37 & 0.82 & 28.34 & 10.51 & 7.52 \\
\hline$(4,3,1)$ & 1326 & 710 & 64.65 & 112 & 0.49 & 0.15 & 25.77 & 10.11 & 7.09 \\
\hline$(4,3,2)$ & 4060 & 2252 & 66.90 & 112 & 0.48 & 0.38 & 25.42 & 10.05 & 7.03 \\
\hline$(4,3,3)$ & 2740 & 1523 & 67.57 & 112 & 0.49 & 0.62 & 25.39 & 10.05 & 7.03 \\
\hline$(4,3,4)$ & 146 & 76 & 68.14 & 112 & 0.50 & 0.83 & 26.00 & 10.14 & 7.13 \\
\hline$(4,4,1)$ & 1030 & 607 & 67.95 & 112 & 0.68 & 0.17 & 24.83 & 9.96 & 6.93 \\
\hline$(4,4,2)$ & 3016 & 1763 & 67.95 & 112 & 0.69 & 0.36 & 24.91 & 9.97 & 6.95 \\
\hline$(4,4,3)$ & 2472 & 1461 & 68.80 & 112 & 0.69 & 0.63 & 24.81 & 9.96 & 6.93 \\
\hline$(4,4,4)$ & 184 & 107 & 69.20 & 112 & 0.69 & 0.85 & 24.99 & 9.99 & 6.96 \\
\hline$(4,5,1)$ & 192 & 116 & 64.98 & 112 & 0.85 & 0.16 & 24.63 & 9.93 & 6.90 \\
\hline$(4,5,2)$ & 576 & 347 & 66.38 & 112 & 0.86 & 0.34 & 24.63 & 9.93 & 6.90 \\
\hline$(4,5,3)$ & 160 & 96 & 65.58 & 112 & 0.89 & 0.60 & 24.63 & 9.93 & 6.90 \\
\hline$(4,5,4)$ & 0 & 0 & 0.00 & 0 & 0.00 & 0.00 & 0.00 & 0.00 & 0.00 \\
\hline$(5,1,1)$ & 3510 & 1508 & 80.55 & 112 & 0.16 & 0.13 & 28.27 & 10.50 & 7.51 \\
\hline$(5,1,2)$ & 8454 & 3814 & 80.12 & 112 & 0.17 & 0.37 & 27.66 & 10.40 & 7.41 \\
\hline$(5,1,3)$ & 2522 & 1193 & 81.18 & 112 & 0.19 & 0.59 & 27.11 & 10.32 & 7.31 \\
\hline$(5,1,4)$ & 18 & 8 & 78.14 & 112 & 0.13 & 0.82 & 28.34 & 10.51 & 7.52 \\
\hline$(5,2,1)$ & 1326 & 567 & 79.07 & 112 & 0.34 & 0.14 & 28.34 & 10.51 & 7.52 \\
\hline$(5,2,2)$ & 2566 & 1141 & 79.88 & 112 & 0.34 & 0.38 & 27.84 & 10.43 & 7.44 \\
\hline$(5,2,3)$ & 1126 & 522 & 80.77 & 112 & 0.34 & 0.61 & 27.35 & 10.35 & 7.35 \\
\hline$(5,2,4)$ & 6 & 3 & 76.37 & 112 & 0.25 & 0.86 & 28.34 & 10.51 & 7.52 \\
\hline$(5,3,1)$ & 1628 & 697 & 81.77 & 112 & 0.51 & 0.17 & 28.31 & 10.51 & 7.52 \\
\hline$(5,3,2)$ & 4598 & 2088 & 80.50 & 112 & 0.50 & 0.38 & 27.59 & 10.39 & 7.39 \\
\hline$(5,3,3)$ & 2978 & 1413 & 79.64 & 112 & 0.51 & 0.62 & 27.07 & 10.31 & 7.31 \\
\hline$(5,3,4)$ & 132 & 61 & 78.73 & 112 & 0.52 & 0.85 & 27.45 & 10.37 & 7.37 \\
\hline$(5,4,1)$ & 692 & 327 & 80.62 & 112 & 0.67 & 0.17 & 27.13 & 10.32 & 7.32 \\
\hline$(5,4,2)$ & 2716 & 1353 & 79.66 & 112 & 0.69 & 0.38 & 26.53 & 10.23 & 7.22 \\
\hline$(5,4,3)$ & 2988 & 1534 & 79.54 & 112 & 0.69 & 0.63 & 26.21 & 10.18 & 7.16 \\
\hline$(5,4,4)$ & 254 & 144 & 78.60 & 112 & 0.69 & 0.85 & 25.23 & 10.02 & 7.00 \\
\hline$(5,5,1)$ & 0 & 0 & 0.00 & 0 & 0.00 & 0.00 & 0.00 & 0.00 & 0.00 \\
\hline$(5,5,2)$ & 104 & 63 & 75.71 & 112 & 0.85 & 0.36 & 24.63 & 9.93 & 6.90 \\
\hline$(5,5,3)$ & 0 & 0 & 0.00 & 0 & 0.00 & 0.00 & 0.00 & 0.00 & 0.00 \\
\hline$(5,5,4)$ & 0 & 0 & 0.00 & 0 & 0.00 & 0.00 & 0.00 & 0.00 & 0.00 \\
\hline
\end{tabular}




\begin{tabular}{|r|r|r|r|r|r|r|r|r|r|}
\hline $\mathbf{( 6 , 1 , 1 )}$ & 642 & 274 & 100.83 & 112 & 0.17 & 0.12 & 28.34 & 10.51 & 7.52 \\
\hline $\mathbf{( 6 , 1 , 2 )}$ & 714 & 322 & 99.31 & 112 & 0.17 & 0.37 & 27.67 & 10.41 & 7.41 \\
\hline $\mathbf{( 6 , 1 , 3 )}$ & 254 & 114 & 106.31 & 112 & 0.19 & 0.59 & 27.71 & 10.41 & 7.42 \\
\hline $\mathbf{( 6 , 1 , 4 )}$ & 14 & 7 & 104.16 & 112 & 0.20 & 0.83 & 25.92 & 10.13 & 7.12 \\
\hline $\mathbf{( 6 , 2 , 1 )}$ & 342 & 146 & 112.84 & 112 & 0.31 & 0.13 & 28.34 & 10.51 & 7.52 \\
\hline $\mathbf{( 6 , 2 , 2 )}$ & 260 & 112 & 110.90 & 112 & 0.33 & 0.39 & 28.18 & 10.49 & 7.49 \\
\hline $\mathbf{( 6 , 2 , 3 )}$ & 136 & 61 & 114.02 & 112 & 0.33 & 0.60 & 27.75 & 10.42 & 7.42 \\
\hline $\mathbf{( 6 , 2 , 4 )}$ & 8 & 5 & 139.60 & 112 & 0.30 & 0.86 & 24.63 & 9.93 & 6.90 \\
\hline $\mathbf{( 6 , 3 , 1 )}$ & 702 & 300 & 109.68 & 112 & 0.55 & 0.16 & 28.34 & 10.51 & 7.52 \\
\hline $\mathbf{( 6 , 3 , 2 )}$ & 968 & 436 & 148.36 & 112 & 0.54 & 0.36 & 27.68 & 10.41 & 7.41 \\
\hline $\mathbf{( 6 , 3 , 3 )}$ & 530 & 236 & 176.04 & 112 & 0.52 & 0.61 & 27.81 & 10.43 & 7.43 \\
\hline $\mathbf{( 6 , 3 , 4 )}$ & 24 & 10 & 134.73 & 112 & 0.55 & 0.87 & 28.34 & 10.51 & 7.52 \\
\hline $\mathbf{( 6 , 4 , 1 )}$ & 698 & 304 & 179.12 & 112 & 0.67 & 0.17 & 28.10 & 10.47 & 7.48 \\
\hline $\mathbf{( 6 , 4 , 2 )}$ & 1240 & 562 & 182.33 & 112 & 0.67 & 0.35 & 27.61 & 10.40 & 7.40 \\
\hline $\mathbf{( 6 , 4 , 3 )}$ & 674 & 294 & 341.93 & 112 & 0.65 & 0.61 & 28.10 & 10.47 & 7.48 \\
\hline $\mathbf{( 6 , 4 , 4 )}$ & 48 & 21 & 431.99 & 112 & 0.63 & 0.86 & 28.34 & 10.51 & 7.52 \\
\hline $\mathbf{( 6 , 5 , 1 )}$ & 0 & 0 & 0.00 & 0 & 0.00 & 0.00 & 0.00 & 0.00 & 0.00 \\
\hline $\mathbf{( 6 , 5 , 2 )}$ & 0 & 0 & 0.00 & 0 & 0.00 & 0.00 & 0.00 & 0.00 & 0.00 \\
\hline $\mathbf{( 6 , 5 , 3 )}$ & 0 & 0 & 0.00 & 0 & 0.00 & 0.00 & 0.00 & 0.00 & 0.00 \\
\hline $\mathbf{( 6 , 5 , 4 )}$ & 0 & 0 & 0.00 & 0 & 0.00 & 0.00 & 0.00 & 0.00 & 0.00 \\
\hline
\end{tabular}

